\title{
ACS Chemical \\ Neuroscience
}

\section{Article}

\section{Functionalization and characterization of magnetic nanoparticles for the detection of ferritin accumulation in Alzheimer's disease}

Tamara Fernández, Alberto Martínez-Serrano, Lorena Cussó, Manuel Desco, and Milagros Ramos-Gómez

ACS Chem. Neurosci., Just Accepted Manuscript • DOI: 10.1021/acschemneuro.7b00260 • Publication Date (Web): 03 Jan 2018

Downloaded from http://pubs.acs.org on January 17, 2018

\section{Just Accepted}

"Just Accepted" manuscripts have been peer-reviewed and accepted for publication. They are posted online prior to technical editing, formatting for publication and author proofing. The American Chemical Society provides "Just Accepted" as a free service to the research community to expedite the dissemination of scientific material as soon as possible after acceptance. "Just Accepted" manuscripts appear in full in PDF format accompanied by an HTML abstract. "Just Accepted" manuscripts have been fully peer reviewed, but should not be considered the official version of record. They are accessible to all readers and citable by the Digital Object Identifier (DOI®). "Just Accepted" is an optional service offered to authors. Therefore, the "Just Accepted" Web site may not include all articles that will be published in the journal. After a manuscript is technically edited and formatted, it will be removed from the "Just Accepted" Web site and published as an ASAP article. Note that technical editing may introduce minor changes to the manuscript text and/or graphics which could affect content, and all legal disclaimers and ethical guidelines that apply to the journal pertain. ACS cannot be held responsible for errors or consequences arising from the use of information contained in these "Just Accepted" manuscripts. 


\section{Functionalization and characterization of magnetic nanoparticles for}

2

3

4 Tamara Fernández ${ }^{1}$, Alberto Martínez-Serrano ${ }^{2}$, Lorena Cussó ${ }^{3,4,5}$, Manuel 5 Desco $^{3,4,5}$ and Milagros Ramos-Gómez ${ }^{1,6, *}$

61 Centre for Biomedical Technology (CTB), Universidad Politécnica de Madrid, Spain

72 Department of Molecular Biology and Centre for Molecular Biology "Severo Ochoa"

8 (CBMSO), Universidad Autónoma de Madrid and Consejo Superior de Investigaciones

9 Científicas, Madrid, Spain.

103 Departamento de Ingeniería Biomédica e Ingeniería Aeroespacial, Universidad Carlos

11 III de Madrid, 28911 Leganés, Spain.

124 Instituto de Investigación Sanitaria Gregorio Marañón, 28007 Madrid, Spain.

135 Centro de Investigación Biomédica en Red de Salud Mental (CIBERSAM), 28029

14 Madrid, Spain

156 CIBER de Bioingeniería, Biomateriales y Nanomedicina (CIBER-BBN), Madrid, 16 Spain.

$17 *$ Corresponding author 
1 Abstract

2 Early diagnosis in Alzheimer's disease (AD), prior to the appearance of marked clinical

3 symptoms, is critical to prevent irreversible neuronal damage and neural malfunction that leads

4 to dementia and death. Therefore, there is an urgent need to generate new contrast agents which

5 reveal by a non-invasive method the presence of some of the pathological signs of AD.

6 In the present study we demonstrate for the first time a new nanoconjugate composed of

7 magnetic nanoparticles bound to an anti-ferritin antibody, which has been developed based on

8 the existence of iron deposits and high levels of the ferritin protein present in areas with a high

9 accumulation of amyloid plaques (particularly the subiculum in the hippocampal area) in the

10 brain of a transgenic mouse model with five familial AD mutations.

11 Both in vitro and after intravenous injection, functionalized magnetic nanoparticles were able to

12 recognize and bind specifically to the ferritin protein accumulated in the subiculum area of the

13 AD transgenic mice.

\section{Keywords}

15 Iron oxide nanoparticles, nanoconjugates, ferritin, iron deposits, microglia, Alzheimer's disease.

\section{Introduction}

17 Alzheimer's disease (AD) is a progressive neurodegenerative disorder, with no known

18 prevention or cure, which affects approximately 47 million patients worldwide ${ }^{1}$. At present, a

19 definitive diagnosis of $\mathrm{AD}$ is only possible after the patient's death, when the presence of

20 amyloid plaques and tangles in the brain parenchyma can be revealed by histological

21 examination ${ }^{2}$. Current diagnostic practices, including assessments of clinical history to detect

22 changes in behavior, physical examination, neuropsychiatric testing (Mini-Mental State

23 Examination, MMSE), diagnostic laboratory tests and neuroimaging, can only make a

24 "probable" diagnosis of $\mathrm{AD}^{3}$. 
1 To date, the best-established biomarkers for the detection and monitoring of AD include

2 measures of $\beta$ amyloid peptide and tau in cerebrospinal fluid, hippocampal atrophy as assessed

3 by magnetic resonance imaging (MRI), reduction in the rate of glucose metabolism in the brain,

4 assessed by positron emission tomography (PET) with fluorodeoxyglucose, and brain

5 accumulation of $\beta$ amyloid peptide visualized by PET using Pittsburgh Compound $\mathrm{B}^{3},{ }^{4}$. None of

6 these methods, alone or in combination, provide high accuracy in the early diagnosis of

7 pathology. Therefore, great emphasis has been placed on the search for biomarkers indicative of

$8 \mathrm{AD}$, but most attempts to date have had limited success ${ }^{5}$.

9 With the improvements in imaging technologies in recent years, there has been a growing interest in developing methods to visualize amyloid plaques in $\mathrm{AD}$, especially in transgenic

11 mice, using methods that could eventually be applied to humans ${ }^{6}, 7$. The therapeutic approaches

12 currently developed show that the available therapies are more effective when applied at very

13 early stages, when a low burden of amyloid plaques can be detected ${ }^{8},{ }^{9}$.Therefore, early

14 diagnosis of the disease is a critical issue.

15 MRI has a higher spatial resolution than PET in the study of whole brain. MRI is a widely available technique that can produce images in both experimental animals and in patients

17 without the need for a radiotracer ${ }^{10}$. Several groups have been able to visualize amyloid plaques

18 in vivo utilizing both the endogenous contrast induced by the plaques attributed to their iron

19 content and by selectively enhancing the signal from amyloid plaques using molecular-targeting

20 vectors labeled with MRI contrast agents ${ }^{11},{ }^{12}$. These data were corroborated using both

21 postmortem brain tissue from $\mathrm{AD}$ patients ${ }^{13}$, and brain tissue from transgenic $\mathrm{AD}$ mice ${ }^{14},{ }^{15},{ }^{16}$.

22 Histological findings associated with AD show the presence of iron deposits in the vicinity of

23 plaques in the brains of patients with the disease ${ }^{17},{ }^{18}$. The intrinsic MRI contrast arising from the

24 iron associated with plaques creates an unexpected opportunity for the noninvasive investigation

25 of the temporal course of development of the plaques in the animal brain, thus reducing

26 intersubject variability ${ }^{16}$. However, the limiting factor of this methodological approach, in

27 which no contrast agent is used, is that only amyloid plaques with a diameter of more than 50 
$1 \mu \mathrm{m}$ can be detected, using acquisition times that generally exceed $2 \mathrm{~h}$. These very long times

2 complicate the acquisition of in vivo images, not only in research animals, but also in the

3 clinical setting.

4 In order to detect amyloid plaques at early stages of the disease, and to diminish the acquisition

5 times of in vivo imaging, several studies have proposed the use of magnetic iron oxide

6 nanoparticles as specific contrast agents for $\mathrm{MRI}^{19},{ }^{20}$. The hypointense effect exhibited by these

7 particles in $\mathrm{T} 2$ and $\mathrm{T} 2 *$ image sequences provides greater contrast in MR images. Therefore, the

8 use of magnetic iron oxide nanoparticles (MNPs) may be a good method for the early diagnosis

9 of $\mathrm{AD}$.

10 Different types of functionalized MNPs have been evaluated in AD models including those

11 coupled to amyloid B peptide $1-40^{21}$, amyloid B peptide $1-30^{22}$, amyloid B peptide $1-42^{11}$ and

12 to peptides highly specific for $\mathrm{A} \beta$ amyloid fibrils ${ }^{23}$, ${ }^{24}$; also by coupling the MNPs to antibodies

13 which specifically recognize amyloid B peptide 1-42 as a component of amyloid

14 plaques ${ }^{25}, 26,{ }^{27},{ }^{19}$. MNPs functionalized with different markers of amyloid plaques, such as

15 Thioflavin $\mathrm{S}^{28}$, Congo $\operatorname{Red}^{29}$, 1,1-dicyano-2-[6-(dimethylamino)naphthalene-2-yl] propene

$16(\mathrm{DDNP})^{30}$ and curcumin ${ }^{31}$, have also been used to target and detect amyloid plaques in $\mathrm{AD}$

17 transgenic mice using ex vivo MRI with long acquisition times.

18 The localized iron accumulation and formation of iron deposits in the brain, together with

19 changes in the regulation of iron-storage and the association of iron with several proteins is

20 evident in several neurodegenerative diseases, including $\mathrm{AD}^{32}, 33$. Proteomic analysis has also

21 shown higher levels of ferritin, the main protein that stores and transports iron in vertebrates, in

22 the hippocampal region of AD patients compared to healthy individuals ${ }^{34}$. Moreover, iron and

23 ferritin are deposited in close proximity to amyloid plaques in the cerebral cortex of $\mathrm{AD}$

24 patients, as determined in post-mortem specimens ${ }^{35}, 36$.

25 The present manuscript presents a novel nanoconjugate based on MNPs bound to an anti-ferritin

26 antibody, which could be a useful tool to detect increases in the expression of ferritin in the 
1 brain parenchyma of transgenic mice with five familial Alzheimer's disease mutations

2 (5XFAD) by $\mathrm{MRI}^{37}$. This nanoconjugate showed a high specific binding to the ferritin protein

3 present in the subiculum of 5XFAD mice after being injected intravenously, while non-

4 functionalized MNPs could not be detected in the same brain region after injection. The results

5 demonstrated that the functionalization of MNPs with the anti-ferritin antibody generated a

6 specific contrast agent useful for detecting the presence of ferritin in the brain parenchyma of

7 the 5XFAD mice, and consequently the presence of iron deposits in the vicinity of amyloid

8 plaques, one of the hallmarks of $\mathrm{AD}$.

\section{$9 \quad$ Results and Discussion}

10 We report here a novel method for the selective marking of the protein ferritin, present in areas

11 with a high accumulation of amyloid plaques, with functionalized magnetic nanoparticles. This

12 novel nanoconjugate, which selectively marked ferritin, might be used in the near future as a

13 contrast agent for MRI enabling the noninvasive early detection of AD.

14 The development of biofunctionalized devices could become a useful tool in diagnosis and therapy of several neuropathologies and become a strategy to deepen knowledge in cell biology and histopathology in neuroscience.

\section{Iron and ferritin accumulation in 5XFAD mice}

18 There is some evidence for altered iron metabolism in $\mathrm{AD}$, including alterations in iron accumulation and changes in transferrin and ferritin levels ${ }^{17}$. Striking iron accumulation has been closely associated with amyloid plaques, neurofibrillary tangles, and neuropil threads in clinical cases of $\mathrm{AD}^{38}$. Increased levels of ferritin have also been observed by proteomic analysis within the hippocampal region in $\mathrm{AD}$ patients compared to healthy individuals ${ }^{34}$. To

23 determine whether these highly relevant histological findings were also present in 5XFAD mice,

24 the presence of iron was evaluated in 9-month-old 5XFAD transgenic and nontransgenic mice

25 by Prussian blue staining. Brain sections from nontransgenic mice showed no obvious Prussian

26 blue staining, indicating a lack of iron accumulation in the brain (Figure 1A). However, iron 
1 burden was obvious in the subiculum of 5XFAD mice (Figure 1B), an area usually containing a

2 high number of amyloid plaques ${ }^{37}$. In fact, when brain sections were stained with Thioflavin S,

3 a marker of amyloid plaques, a strong signal could be detected in the subiculum area only in the

4 5XFAD mice (Figure 1D), indicating a high density of amyloid plaques coinciding with the

5 strong accumulation of iron in this hippocampal region. As expected, amyloid protein was not

6 detected in nontransgenic mice (Figure 1C).

7 Since high iron content was observed in SXFAD mice in the hippocampal area, we stained

8 similar brain sections with an anti-ferritin antibody to determine the levels of this iron-binding

9 protein in this region. While the presence of this protein in control mice was almost negligible

10 (Figure 1E), in 5XFAD brain sections, strong labeling for ferritin protein was evident in the

11 subiculum (Figure 1F).

12 This high expression of ferritin in the subiculum of the 5XFAD transgenic mice coincided

13 perfectly with the presence of a high number of amyloid plaques in the same area (arrows in

14 Figure 1D and 1F).

15 The regional accumulation of iron deposits in the brain, together with changes in the regulation

16 of iron storing proteins and the association of iron with neuropathology is evident in several

17 neurodegenerative diseases, including AD, Parkinson's disease, multiple sclerosis and

18 Huntington's disease, where the accumulation of iron in the brain corresponds to the regions of

19 greatest neuronal degeneration ${ }^{39-44}$. Iron accumulation in these neurodegenerative diseases

20 occurs in different brain regions. In $\mathrm{AD}$, iron accumulation occurs in the hippocampus ${ }^{40}$. In

21 Huntington's disease, an increased iron burden in the cortex and striatum has been shown in

22 both patients and transgenic mouse models for the disease ${ }^{41}$. In patients with Parkinson's

23 disease, accumulation of iron occurs in the substantia nigra ${ }^{42}$. In the case of multiple sclerosis,

24 an increase in iron in the spinal cord white matter has also been described ${ }^{43}$. Therefore, a

25 specific contrast agent able to detect iron deposits by MRI could be useful for the diagnosis of

26 several neurodegenerative diseases. Furthermore, each neurodegenerative disorder could then be

27 distinguished by determining the brain area(s) where such iron accumulations occur. In this 
1 way, the developed nanoconjugate would be a useful tool to detect $\mathrm{AD}$, depending on the

2 location of the iron accumulations in the brain.

3 Iron deposits and a strong immunoreactivity for ferritin have been observed near the amyloid

4 plaques in the cortex and in the hippocampus of $\mathrm{AD}$ patients ${ }^{35},{ }^{36}$. Ferritin accumulation was

5 almost exclusively associated with reactive microglial cells, which appeared to have greatly

6 proliferated $^{36}$. To determine if iron and ferritin accumulations in 5XFAD mice were deposited

7 close to the amyloid plaques, a double staining was performed using an antibody specific for the

8 ferritin protein and a specific marker for amyloid plaques (Thioflavin S). Cells labeled with the

9 anti-ferritin antibody were found near the amyloid plaques, with their processes in close contact

10 with and surrounding the plaques in 5XFAD brains (Figure 2). In brain slices obtained from AD

11 patients, astrocytes and microglia have been shown to be associated with the amyloid plaques,

12 where they show an activated, amoeboid state surrounding the plaques with their processes ${ }^{44,45}$.

13 In the case of 5XFAD mice, staining with the astrocytic marker for glial fibrillary acidic protein

14 (GFAP) showed a high number of GFAP-positive cells throughout the subiculum with no

15 colocalization with ferritin positive cells (Figure 3C). However, the selective labeling of microglial cells using tomato lectin, a protein with specific affinity for poly-N-acetyl

17 lactosamine sugar residues that are found on the plasma membrane and in the cytoplasm of

18 microglia, established a high colocalization of this marker with ferritin (Figure 3D). These

19 results indicate that microglial cells colocalized with ferritin and were abundant in areas

20 showing a high density of ferritin and amyloid plaques (Figures 3A and 3B, respectively).

21 Previous studies suggested that in the brain of patients with $\mathrm{AD}$, the enhanced ferritin

22 expression indicated microglia degeneration instead of reflecting an activated state ${ }^{45},{ }^{46}$. The

23 enhanced expression of ferritin protein has been described to increase the susceptibility of

24 microglia to degeneration, particularly in the aging brain $^{45}$. Senescent microglia may be less

25 efficient in maintaining iron homeostasis, and free iron could promote oxidative damage in

26 neurodegenerative diseases. Therefore, in brains affected by AD, increased expression of ferritin

27 could constitute a marker of microglial degeneration. 
1 These results indicate that the increased presence of ferritin in AD brains could serve as an

2 interesting biomarker to reveal the presence and localization of amyloid plaques. Therefore,

3 conjugation of an anti-ferritin antibody with magnetic nanoparticles could produce a specific

4 contrast agent useful for noninvasively detecting the presence of amyloid plaques in the brain

5 using MRI.

6 Coupling of the anti-ferritin antibody to MNPs

$7 \quad$ An anti-ferritin polyclonal antibody was immobilized onto 50nm dextran-coated MNPs as

8 described in the methods section. A polyclonal antibody that recognizes multiple epitopes on

9 the same antigen was chosen due to its high affinity and tolerance to possible changes in the

10 antigen $^{47}$. The preparation of the nanoconjugates was based on the carbodiimide method ${ }^{48}$,

11 leading to the formation of a very stable complex. The efficiency of the antibody binding to the

12 MNPs was determined by a dot-blot assay (Figure 4). Dot-blot analysis confirmed a high level

13 of anti-ferritin antibody binding to MNPs, since only small traces of free anti-ferritin antibody

14 were detected in the unbound fraction (Figure 4C); a high amount of anti-ferritin antibody

15 present at the beginning of the coupling reaction (Figure 4A) could be detected conjugated to

16 the MNPs in the MNPs-anti-ferritin fraction (Figure 4B) after the coupling reaction. Therefore,

17 the binding of the anti-ferritin antibody to the MNPs to form the MNP-anti-ferritin conjugate

18 was highly effective.

19 These previous results were also confirmed by protein quantification using an improved

20 Bradford protein assay permitting quantification of low protein concentrations ${ }^{49}$. The binding

21 efficiency was estimated to be about $30 \pm 14$ molecules of anti-ferritin bound per nanoparticle.

22 Binding of the antibody to the MNPs may increase the final hydrodynamic diameter of the

23 MNPs as previously described for similar $\mathrm{MNPs}^{50}$ in which the antibody bound to the MNPs

24 increased twofold their final hydrodynamic diameter.

\section{Cell viability after incubation with MNPs}


1

2

3

4

5

6

7

8

9

1 To discard a potential neurotoxicity of the MNPs, we determined that the incubation of human

2 neuroblastoma SH-SY5Y cells with MNPs and MNPs-anti-ferritin was feasible and did not

3 impair cell viability in vitro. SH-SY5Y cells were incubated with both types of MNPs and

4 tested for viability using doses up to $200 \mu \mathrm{g} / \mathrm{mL}$ and incubation times of 72 hours, which did not

5 significantly affect neuroblastoma cells survival, as evaluated by the lactate dehydrogenase

$6(\mathrm{LDH})$ activity assay (Figure 5A). Once determined that MNPs did not induce a loss of cell

7 viability on SHSY5Y cell line, we analyzed the effect of MNP and MNPs-anti-ferritin on

8 primary cell cultures obtained from mouse brains, in order to discard an effect of the MNPs on

9 some specific type of brain cells (i.e.,neurons, astrocytes, or microglial cells). The results

10 showed that cell viability rates were similar in control and MNPs-treated cell cultures (Figure

$115 \mathrm{~B}$ ) and that the number of neurons and astrocytes did not decrease in the presence of MNPs or

12 MNPs-anti-ferritin with respect to untreated control cells (Figure 5C). The number of microglia

13 cells stained with the anti-Ibal antibody were higher in MNPs-treated cells compared to

14 untreated control cells (in which no microglial cells were detected), indicating that MNPs were

15 preferentially taken up by the microglial cells (Figure 5D), although the viability of the cells

16 during the periods of time analyzed was not affected.

17 These results suggested that although iron oxide nanoparticles could induce oxidative stress ${ }^{51}$,

18 the levels of intracellular iron accumulation resulting from the incubation with MNPs and the

19 presence of the antibody in the case of the nanoconjugate MNP-anti-ferritin, did not induce

20 acute cell toxicity at the times and concentrations analyzed. In addition, Mahmoudi and

21 coworkers ${ }^{52}$ have shown that the interaction of nanoparticles with serum proteins forming the

22 nanomaterial's protein corona inhibits the formation of $\mathrm{A} \beta$ fibril upon their entrance to the

23 biological medium.

\section{In vitro specificity of the MNP-anti-ferritin conjugate}

25 To verify the in vitro specificity of the MNP-anti-ferritin conjugate, fixed brain sections from 9-

26 month-old 5XFAD and nontransgenic mice, with a high (Figure 6A) and low (Figure 6E)

27 expression of ferritin, respectively, were incubated with the MNP-anti-ferritin conjugate. The 
1 presence of the MNP-anti-ferritin conjugate bound to the subiculum in brain slices was detected

2 using an anti-rabbit-Cy3 antibody which recognized only the polyclonal ferritin antibody bound

3 to the MNPs. The results indicated a strong binding in the case of 5XFAD mice (Figure 6B and

$4 \quad 6 \mathrm{C})$ and a nearly absent, undistinguishable from background, binding in nontransgenic mice

5 (Figure 6F and 6G). The accumulation of MNPs in the slices could even be observed by

6 transmission light microscopy as highly localized and crowded black dots in 5XFAD (Figure

7 6D). This type of signal was undetectable in nontransgenic mice (Figure 6H).

8 As evidenced in Figure 6, the accumulation of the MNP-anti-ferritin conjugate in the subiculum

9 is higher in 5XFAD than in nontransgenic brain sections (compare Figure 6 B-D with panels F-

$10 \mathrm{H})$. The binding of MNP-anti-ferritin conjugate colocalized with cells showing clear-cut, high

11 expression of ferritin in 5XFAD (Figure 6A) in comparison with nontransgenic (Figure 6E)

12 mice.

13 Also, the accumulation of bound MNP-anti-ferritin conjugate in the subiculum of 5XFAD mice

14 regionally correlates with the presence of amyloid plaques and ferritin in the subiculum,

15 previously shown in Figure 1D and 1F, respectively. As expected, in brain sections from

16 nontransgenic mice (Figure 6F-H), very few MNP-anti-ferritin nanoconjugate could be detected

17 (Figure 6G), and the black stain observed by transmission light microscopy was absent (Figure

$186 \mathrm{H}$ ), consistent with the very weak expression of ferritin in the subiculum of nontransgenic mice

19 (Figure 6E).

20 Consequently, these results indicated that the MNP-anti-ferritin conjugate specifically binds and

21 detects the enhanced expression of the ferritin protein that occurs in the subiculum of 9-month-

22 old 5XFAD mice in vitro.

\section{In vivo specificity of the MNP-anti-ferritin conjugate}

24 Once the in vitro specificity of the MNP-anti-ferritin nanoconjugate was confirmed in fixed

25 5XFAD brain sections, its efficiency was tested in vivo after intravenous injection in 5XFAD

26 mice. Since the previous in vitro results indicated the absence of detectable signal in control 
1 animals, wild type mice were not used in these experiments to reduce the number of animals

2 used in adherence to the 3Rs principles. Plain non-functionalized MNPs and MNP-anti-ferritin

3 conjugates were intravenously injected into the retro-orbital sinus of 5XFAD mice. Six hours

4 after intravenous administration of the MNPs, 5XFAD brains were fixed and subsequently

5 analyzed by histological analyses to localize the final distribution of the MNPs. The

6 accumulation of ferritin protein and amyloid plaques in the subiculum of transgenic mice was

7 again confirmed using an anti-ferritin antibody and Thioflavin-S staining, respectively (Figure

$8 \quad 7 A)$. Serial sections were stained with the secondary polyclonal Cy3-antibody alone to detect

9 the presence of the MNP-anti-ferritin conjugates in the subiculum of 5XFAD mice previously injected with the nanoconjugate (Figure 7B). Moreover, the MNPs were fluorescently labeled using an antibody against their coating (antidextran-FITC; Figure 7D and 7G). The results

12 shown in Figure 7 demonstrate that the MNP-antiferritin nanoconjugates injected intravenously

13 accumulate in the subiculum area of the transgenic 5XFAD brains, where a high number of 14 amyloid plaques and an enhanced expression of ferritin exist (Figure 7A-E). In contrast, when non-functionalized MNPs were injected intravenously in 5XFAD mice, only very few, occasional, MNPs could be detected in the subiculum area (Figure $7 \mathrm{~F}-\mathrm{H}$ ), demonstrating a high specificity of the MNP-anti-ferritin conjugates to reveal the accumulation of ferritin in the brain of living 5XFAD mice. These results also indicated that non-functionalized MNPs did not bind to 5XFAD brain parenchyma in a non-specific manner after intravenous injection, demonstrating a lack of nonspecific binding of the non-functionalized MNPs to the iron deposits

21 found in the subiculum of 5XFAD mice. Moreover, the robust colocalization (Figure 7E) of the

22 ferritin antibody signal (Figure 7C) and the MNPs (Figure 7D) indicated that the MNP-anti-

23 ferritin nanoconjugate was highly stable under physiological in vivo conditions, avoiding

24 potential opsonization when circulating through the bloodstream and eluding clearance by the reticuloendothelial system before reaching its target.

26 The ferritin protein also circulates in the plasma, where it transports iron. Ferritin in plasma has

27 been shown to enter the brain parenchyma through the blood brain barrier (BBB) using the 
1 ferritin $\mathrm{H}$ receptor present on the plasma membrane of endothelial cells that form the $\mathrm{BBB}^{53,54}$.

2 Therefore, a theoretical drawback of the present method would be that it might be possible that

3 plasmatic ferritin could saturate all the antibody recognition sites available on the MNPs, thus

4 preventing the binding of the nanoconjugate to the ferritin present in the brain parenchyma. This

5 would seriously limit the efficacy of the iron-ferritin detection method, and its potential use as a

6 diagnostic tool. Although we cannot exclude some binding to plasma ferritin, our results

7 indicate that the MNP-anti ferritin conjugate has enough free binding sites to recognize the

8 ferritin accumulated in the subiculum of 5XFAD mice.

9 Based on our results, we propose that the MNPs conjugated to anti-ferritin antibody could be a

10 useful tool for the imaging and detection of iron accumulations in the brain parenchyma of $\mathrm{AD}$

11 patients. Future work will be needed to increase the binding capacity and affinity of the

12 nanoconjugate. A limitation of our method is the need to open the BBB with the use of

13 mannitol.

14 Although intravenous mannitol injection has been used safely in patients under a variety of

15 clinical settings $\mathrm{s}^{55}$, a potential future clinical use of this contrast agent would require further

16 modifications including the coupling of MNPs with specific proteins actively transported into

17 the brain ${ }^{22}$ or their PEGylation ${ }^{11}$ in order to increase the ability of the MNPs to cross the BBB

18 and avoid the use of mannitol.

19 Ex vivo brain MRI

20 After confirming that MNP-anti-ferritin nanoconjugate injected intravenously specifically

21 bound to the subiculum region in transgenic 5XFAD brains, MR images from the same area

22 were acquired from a different set of experimental animals after the injection of non-

23 functionalized and functionalized MNPs as a preliminary study. Nontransgenic mice injected

24 with MNP-anti-ferritin and 5XFAD mice without MNPs did not show any non-specific marks in

25 MR images (data not shown). Although there were no evident marks on MR images of the

26 injected MNPs (Figure $8 \mathrm{~A}$ and $8 \mathrm{~B}$ ), a significant decrease in $\mathrm{T} 2 *$ value in both the right and 
1 left hippocampus was found in 5XFAD animals injected with functionalized MNPs as

2 compared to 5XFAD mice injected with non-functionalized MNPs (Figure $8 \mathrm{C}$ ). Therefore,

3 changes in $\mathrm{T} 2 *$ value in MNP-anti-ferritin injected $5 \mathrm{XFAD}$ mice could be attributed to ferritin

4 accumulation and consequently to amyloid plaque deposition in the transgenic mice, as

5 previously demonstrated by histological analysis (Figure 7). Therefore, our results are consistent

6 with the literature. Yang et $\mathrm{al}^{56}$ also reported a decrease of $\mathrm{T} 2 *$ value in the hippocampus after

7 nanoparticle administration in both in vivo and ex vivo MRI studies.

8 In order to increase the binding of the nanoconjugate MNPs-anti-ferritin to the transgenic mouse

9 brains, higher amounts of anti-ferritin antibody could be used for the coupling reaction.

10 Moreover, the dosage we used of MNP-anti-ferritin at $20 \mu \mathrm{mol} \mathrm{Fe} \mathrm{O}_{4} / \mathrm{kg}$ body weight is far

11 from the range of preclinical MRI applications for which contrast agents are typically injected

12 intravenously by femoral or tail vein, at $200 \mu \mathrm{mol} \mathrm{Fe} \mathrm{O}_{4} / \mathrm{kg}$ body weight for diagnostic

13 purposes $^{11,29}$ and similar to the doses of commercial MNPs (i.e., Endorem ${ }^{\circledR}$, Resovist $^{\circledR}$, or

$\left.14 \mathrm{Feridex}^{\circledR}\right)$ used in clinical trials $\left(15 \mu \mathrm{mol} \mathrm{Fe}_{3} \mathrm{O}_{4} / \mathrm{kg}\right.$ body weight $)$. Therefore, since no

15 cytotoxicity of the MNPs used to synthesize the nanoconjugate was observed even at the highest concentration used (Figure 5), a higher dose of MNPs could be injected in vivo to induce qualitative changes on brain MRI allowing visual ferritin accumulation in the future.

The specificity of this nanoconjugate is important because, to date, the detection of iron deposits associated with AD by MRI is only possible when a high concentration of iron is deposited around the amyloid plaques ${ }^{12}$, preventing early diagnosis of the disease. The use of contrast agents like the one described here, based on MNPs functionalized with antibodies directed against the protein that stores iron, would allow an earlier detection of the accumulation of ferritin and, hence, of iron, as we have shown in the present work. This would allow an early diagnosis of the disease, since the presence of iron deposits in the brains of patients with $\mathrm{AD}$ is

25 one of the most common histopathological features associated with the disease ${ }^{17}$. Iron is known

26 to promote aggregation of $\beta$-amyloid peptide and therefore a large number of therapeutic trials

27 are currently aimed at reducing elevated levels of iron in the brains of AD patients ${ }^{57}$. Thus, an 
1 effective method for early and sensitive detection of iron levels in the brains of AD patients is

2 necessary.

3 These preliminary results of detecting ferritin accumulation in SXFAD mice show a potential

4 future high-specificity tool for diagnosis of Alzheimer's disease.

\section{$5 \quad$ Methods}

\section{$6 \quad$ Animals}

7 Hemizygous $5 \mathrm{xFAD}$ mice obtained from the Jackson Laboratory were used as a model of

8 Alzheimer's disease ${ }^{37}$. These $5 \mathrm{xFAD}$ mice carry five mutations associated with familial AD

9 (Swedish (K670N, M671L), Florida (I716V) and London (V717I) mutations in amyloid

10 precursor protein (APP) and M146L and L286V mutations in presenilin 1 (PS1)) and develop

11 several features of $\mathrm{AD}$ described in humans, such as the presence of amyloid plaques, which

12 appear as early as 2 months of age in these mice ${ }^{37} . \mathrm{N}=3$ Nine month old male 5XFAD

13 transgenic mice and $n=3$ their wild-type (nontransgenic) littermates were used for all

14 experiments as proof of concept to determine the specificity of the nanoconjugate. All

15 procedures involving the use of animals were reviewed and approved by the local Animal Care

16 Committee (Universidad Politécnica de Madrid) according to the guidelines of the European

17 Community $(\mathrm{ECC} / 566 / 2015)$.

\section{Histological analysis}

19 5XFAD and nontransgenic mice (9-month old) were anesthetized with an overdose of chloral

20 hydrate and intracardially perfused with freshly prepared 4\% paraformaldehyde (in $0.1 \mathrm{M}$

21 phosphate buffer, $\mathrm{pH}$ 7.4). Brains were removed, postfixed for $12 \mathrm{~h}$ in the same fixative at $4{ }^{\circ} \mathrm{C}$,

22 and dehydrated in $30 \%$ sucrose solution at $4{ }^{\circ} \mathrm{C}$ until sunk. Thirty- $\mu \mathrm{m}$ thick coronal sections

23 were collected using a freezing microtome (Leica SM 2400).

24 Prussian blue iron staining was used to visualize the iron deposits in the brain sections of

25 5XFAD and nontransgenic mice ${ }^{58}$. A previous inactivation of endogenous peroxidase activity in 
1

2

3

4

5

6

7

8

9

1 the tissue was performed by incubating the sections in $3 \% \mathrm{H}_{2} \mathrm{O}_{2}$ and $10 \%$ methanol in

2 phosphate buffered saline (PBS); samples were maintained at room temperature in the dark with

3 shaking for 30 minutes. After rinsing with PBS, sections were incubated in the Prussian blue

4 solution ( $2 \%$ potassium ferrocyanide trihydrate (Sigma \# P-3289), 2\% HCl, 1\% Triton X-100 in

5 distilled $\mathrm{H}_{2} \mathrm{O}$ ) for 30 minutes. Samples were then washed twice in distilled $\mathrm{H}_{2} \mathrm{O}$ and treated with

6 a solution of Ni-DAB ( $5 \mathrm{mg}$ of 3, 3'-diaminobenzidine (Sigma), $35 \mu \mathrm{L}$ of $8 \% \mathrm{NiCl}_{2}$ and $4 \mu \mathrm{L}$ of

$730 \% \mathrm{H}_{2} \mathrm{O}_{2}$ in $10 \mathrm{~mL}$ of PBS) for 15 minutes. Sections were rinsed in PBS and mounted onto

8 gelatinized glass slides (Menzel-Glaser). The slides were dried overnight, successively

9 dehydrated with ethanol, delipidated with xylene and coverslipped with DPX mounting

10 medium.

11 Thioflavin $\mathrm{S}$ was used for the specific staining of amyloid plaques in brain sections from

12 5XFAD mice ${ }^{49}, 59$. Brain sections from 5 XFAD and nontransgenic mice were mounted onto

13 polylysine- treated slides (Thermo Scientific) and allowed to dry for $48 \mathrm{~h}$. Sections were then

14 incubated in $0.05 \%$ Thioflavin-S (Sigma) diluted in 50\% ethanol for 30 minutes, protected from

15 light. After the incubation, sections were rinsed twice in $50 \%$ ethanol and once in distilled $\mathrm{H}_{2} \mathrm{O}$.

16 The slides were dried overnight and coverslipped with Mowiol mounting medium.

\section{Immunohistochemistry}

18 Thirty- $\mu \mathrm{m}$ serial sections obtained from $5 \mathrm{XFAD}$ and nontransgenic mice were also assessed by

19 immunohistochemistry using a polyclonal antibody against ferritin (1:1000; Sigma) and a monoclonal antibody against GFAP (1:1000; Sternberger). Briefly, free-floating sections were incubated overnight at $4{ }^{\circ} \mathrm{C}$ with the primary antibodies diluted in PBS with $2 \%$ nonspecific serum. Sections were rinsed four times in PBS for a total time of $1 \mathrm{~h}$ and then incubated for $2 \mathrm{~h}$ with the secondary antibodies diluted in PBS (anti-mouse or anti-rabbit Cy3- conjugated antibodies, 1:200, all from Jackson Immunoresearch). Streptavidin-FITC (1:300; Vector Labs) and coverslipped with Mowiol. 


\section{Preparation of MNP-anti-ferritin nanoconjugate}

2 MNP-anti-ferritin conjugates were prepared according to the carbodiimide method ${ }^{48}$. Briefly, 1

$3 \mathrm{mg}$ of $50 \mathrm{~nm}$ in diameter $\mathrm{Fe}_{3} \mathrm{O}_{4}$-dextran coated MNPs with a magnetite content of $35 \%(\mathrm{w} / \mathrm{w})$

4 and functionalized with -COOH groups (Kisker \# PMC-50) were washed with $0.1 \mathrm{M} 2-(\mathrm{N}-$

5 morpholino)ethanesulfonic acid (MES) buffer at pH 5.5 and diluted to a final volume of $500 \mu \mathrm{L}$

6 in MES buffer containing $20 \mathrm{mg}$ of freshly prepared 1-ethyl-3-(3-dimethylaminopropyl)

7 carbodiimide (EDC) and $40 \mathrm{mg}$ of sulfo- $N$-hydroxysuccinimide (NHS). The particles were

8 mixed on a shaker for $2 \mathrm{~h}$ at room temperature. After incubation, the particles were washed

9 twice with $1 \mathrm{~mL}$ MES buffer at $\mathrm{pH} 5.5$ and the activated particles were resuspended in $0.5 \mathrm{~mL}$

10 MES buffer at $\mathrm{pH}$ 5.5. Amine group-containing ligands (150 $\mu \mathrm{g}$ of a polyclonal anti-ferritin

11 human antibody. Sigma-Aldrich Cat. No. F5012) were added to the activated particles and the

12 suspension was mixed on a shaker overnight at room temperature. The conjugate was washed

13 three times with $1 \mathrm{~mL}$ PBS, centrifuged each time at $5000 \mathrm{rpm}$ for 5 minutes, resuspended in

$140.5 \mathrm{~mL}$ of PBS, and kept at $4{ }^{\circ} \mathrm{C}$ until use.

\section{Dot-blot assay}

16 To test the efficiency of the coupling reaction of the anti-ferritin antibody to the MNPs, $1 \mu \mathrm{L}$

17 drops of each solution used in the preparation of the MNP-anti-ferritin conjugate (anti-ferritin

18 antibody, MNPs alone, medium containing unbound anti-ferritin antibody, and MNP-anti-

19 ferritin conjugate) were deposited onto a nitrocellulose membrane strip (Bio-Rad). After drying

20 at room temperature, dot-blots were blocked for 1 hour at room temperature with 5\% skim milk

21 in Tris-buffered saline ( $500 \mathrm{mM} \mathrm{NaCl}$ in $20 \mathrm{mM}$ Tris, $\mathrm{pH}$ 7.4) containing $0.05 \%$ Tween 20

22 (TTBS) and then incubated with a goat anti-rabbit peroxidase-conjugated antibody (1:5000; Life

23 Technologies) for 1 hour at room temperature. Immunoreactivity was detected using the ECL

24 Western blotting detection system (Amersham Biosciences). In addition, protein concentrations

25 in the coupling reaction (total and unbound antibody) were determined by an improved

26 Bradford protein assay permitting quantification of low protein concentrations ${ }^{60}$, in order to

27 confirm dot-blot results. The number of anti-ferritin molecules was calculated as previously 
1

2

3

4

5

6

7

8

9

1 described $^{61}$. In both assays, a control was performed to discard the precipitation of the antibody

2 during the coupling reaction.

\section{Cell viability assays}

4 Human neuroblastoma cells (SH-SY5Y; ECACC No. 94030304) were maintained in DMEM

5 medium supplemented with $10 \%$ heat-inactivated fetal bovine serum, $2 \mathrm{mM}$ L-glutamine,

$6 \quad 0.1 \mathrm{mM}$ nonessential amino acids, $100 \mathrm{U} / \mathrm{mL}$ penicillin and $100 \mathrm{mg} / \mathrm{mL}$ streptomycin (Life

7 Technologies). The cell line was maintained at $37^{\circ} \mathrm{C}$ in a humidified incubator of $5 \% \mathrm{CO}_{2}: 95 \%$

8 air and passaged twice per week. For the cell viability assay, cells were plated on 96 well plates

$9\left(15 \times 10^{3}\right.$ cells/well, in triplicate for each condition). Twenty four hours after plating, the cells

10 underwent treatment with MNPs and MNPs-anti-ferritin. Cell viability was evaluated 72 hours

11 after the incubation with the MNPs by the LDH assay, using the Cytotoxicity Detection kit

12 (Roche) and following the manufacturer's instructions. Briefly, after the incubation time with

13 the MNPs, cells were rinsed in PBS and lysed with 1\% Triton X-100. Lysate was then collected

14 after centrifugation at $1500 \mathrm{rpm}$ for 5 minutes to remove cell debris. Cell-free supernatants were

15 incubated with the kit's substrate mixture. LDH activity was determined in a coupled enzymatic reaction; during this reaction, the tetrazolium salt is reduced to formazan. The formazan dye was quantified spectrophotometrically at $490 \mathrm{~nm}$. LDH activity present in the medium was expressed as a percentage of the maximum activity, considering $100 \%$ of LDH activity released to the medium as the absorbance obtained when control cells (cells without MNPs) were lysed with $1 \%$ Triton X-100.

21 Cortical mixed neuronal and glial cell cultures were prepared from 18-day-old BCL56 embryos as previously described ${ }^{62}$. Cerebral cortices were enzymatically dissociated in PBS containing $1 \%$ bovine serum albumin, $0.4 \mathrm{mg} / \mathrm{ml}$ papain, and $6 \mathrm{mM}$ glucose. Dissociated cells were collected by centrifugation ( $800 \mathrm{x} \mathrm{g,} 5$ minutes) and resuspended in medium supplemented with $20 \%$ horse serum. Culture medium consisted of Neurobasal with 1\% glutamax-I and B27 supplements (all from Gibco). The cells were then plated at $1 \times 10^{5}$ cells $/ \mathrm{cm}^{2}$ on plastic plates pretreated for 1 day with $10 \mathrm{mM}$ poly-L-lysine and for 2 hours with laminin $(1 \mathrm{mg} / \mathrm{ml})$. The 
1 medium was replaced after 1 day by Neurobasal with 1\% glutamax-I and B27 supplements.

2 Two-thirds of the medium were replaced every second day. Cell cultures were maintained for 7

3 days and then MNPs and MNPs-anti-ferritin were added at $200 \mu \mathrm{g} / \mathrm{mL}$ for 3 days. To visualize

4 the final location of MNPs in cortical cell cultures, red fluorescent MNPs (Chemicell nano-

5 screenMAG/R) were used (Figure 5D). Cells were then fixed in 4\% paraformaldehyde and

6 immunofluorescence was performed using the following primary antibodies: anti- $\beta$-III-tubulin

7 (Sigma) to stain neurons, anti-GFAP (Sigma) to stain astrocytes, and anti-Iba-1 (Sigma) to label

8 microglial cells. Cell nuclei were counterstained with Hoechst 33258 (Molecular Probes). For

9 the cell viability assay, cells were plated on 96 -well plates $\left(15 \times 10^{3}\right.$ cells/well, in triplicate for

10 each condition). Twenty-four hours after plating, the cells underwent treatment with MNPs and

11 MNPs-anti-ferritin. Cell viability was evaluated 72 hours after the incubation with the MNPs by

12 using the Cell Proliferation Assay kit (AppliChem) following manufacturer instructions. This

13 employs 2,3-bis-(2-methoxy-4-nitro-5-sulfophenyl)-2H-tetrazolium-5-carboxanilide salt (XTT).

14 In living cells, mitochondria have the capability to reduce XTT to form an orange-colored,

15 water-soluble dye ${ }^{63}$. Therefore, the concentration of this dye is proportional to the number of

16 metabolically active cells. The absorbance of each well was measured spectrophotometrically at

$17450 \mathrm{~nm}$ by using an ELX808 microplate reader (BioTeK).

\section{In vitro specificity of the MNP-anti-ferritin conjugate}

To test the specificity of MNP-anti-ferritin conjugates, 5XFAD and nontransgenic brain sections were incubated with the MNP-anti-ferritin nanoconjugate $(2 \mathrm{mg} / \mathrm{mL})$. Sections were

21 then washed three times in PBS and incubated for 1hour at room temperature with a goat anti

22 rabbit Cy3 antibody (1:200; Jackson Immunoresearch). Sections were then washed in PBS and

23 distilled water and mounted onto polylysine coated slides (Menzel-Glaser). The slides were

24 dried overnight and coverslipped with Mowiol.

\section{In vivo specificity of the MNP-anti-ferritin conjugate}


1 Mice were anesthetized with a mixture of isoflurane and oxygen $(1.5 \%$ isoflurane per $1 \mathrm{~L}$

2 oxygen) and homeothermy was maintained through a heated water blanket (TP 500 model,

3 Gaymar Industries, Inc, NY, USA) set at $37^{\circ} \mathrm{C}$. To facilitate the penetration of the MNPs

4 through the BBB, $100 \mu \mathrm{L}$ of a solution of mannitol (15\% in PBS; Sigma) was injected into the

5 retro-orbital sinus. Then, 15 minutes later, $150 \mu \mathrm{L}(2 \mathrm{mg} / \mathrm{mL})$ of plain MNPs or MNP anti-

6 ferritin conjugate were intravenously injected (approximately $200 \mu \mathrm{g}$ MNPs $/ \mathrm{mL}$ blood) in the

7 same location ${ }^{64}$. Six hours after injection of the MNPs, mice were intracardially perfused and

8 the brains were fixed as described in the histological analysis section. To identify the presence

9 of the MNP-anti-ferritin nanoconjugate, brain sections were incubated with a secondary anti-

10 rabbit Cy3 antibody (1:200; Jackson Immunoresearch). A monoclonal anti-dextran antibody

11 (1:500; Stem Cell Technologies) and a secondary anti-mouse FITC antibody (1:200; Jackson

12 Immunoresearch) were used to identify the magnetic nanoparticles.

\section{Ex vivo brain MRI}

14 Transgenic 5XFAD mice were injected with MNPs and MNP-anti-ferritin as described in the previous section. Six hours after the injection, mice were transcardially perfused with PBS followed by $4 \%$ PFA. After this process, brains were extracted and immersed in Fomblin

17 (Solvay Solexis Inc., Thorofare, NJ) in order to provide a completely dark background around the brains being imaged. A Bruker 7T scanner Biospec 70/20 was used to perform Multiplegradient echo 3D images with the following parameters: $98 \mu \mathrm{m}$ isotropic spatial resolution, $\mathrm{TR}=200 \mathrm{~ms}$, matrix $=128 \times 128 \times 128,10$ echoes times $(\mathrm{TE})$, first $=2.7 \mathrm{~ms}$ with echo spacing $(\mathrm{ES})=3.57 \mathrm{~ms}, \mathrm{FA}=15^{\circ}$, imaging time $=5$ hours and 7 minutes

22 The apparent transverse relaxation time $\mathrm{T} 2 *$ was measured using the ten-echo train image sets

23 described above in several brain regions defined by region of interest (ROI). Right and left

24 dorsal hippocampus were manually drawn and $\mathrm{T} 2 *$ values were obtained using the

25 quantification tool of ParaVision 5.0 (Bruker, Germany).

\section{Optical microscopy}


1 Analyses and photography of Prussian blue or fluorescence stained samples were carried out

2 using an inverted Leica DMIRB microscope equipped with a digital camera (Leica DC100,

3 Nussloch, Germany). The confocal microscopy analysis was performed using a LSM 510

4 META confocal microscope coupled to an inverted microscope Axiovert200 (Zeiss) with image

5 capture software Zeiss ZEN 2008 sp2.

\section{Statistical analysis}

7 Results are presented as mean \pm S.E.M. of at least 3 independent experiments. The data were

8 analyzed by single factor analysis of variance followed by the post hoc Tukey's honestly

9 significant difference test. A significance level of $\mathrm{p}<0.05$ was chosen. STATISTICA software

10 (StatSoft, Tulsa, OK) was utilized for all statistical tests.

11 Safety

12 Not applicable

13 Abbreviations

14 AD: Alzheimer's disease

15 PET: positron emission tomography

16 MNPs: magnetic iron oxide nanoparticles

17 MRI: magnetic resonance imaging

18 5XFAD: transgenic mice model with five familial Alzheimer's disease mutations

19 PBS: phosphate buffered saline

20 GFAP: glial fibrillary acidic protein

21 LDH: lactate dehydrogenase

22 MES: 2-(N-morpholino) ethanesulfonic acid

23 BBB: blood brain barrier 
1

2

3

4

6

7

8

9

10

1 DDNP: 1,1-dicyano-2-[6-(dimethylamino)naphthalene-2-yl] propene

2 Author Information

$3 *$ Corresponding autor

4 Milagros Ramos-Gómez*

5 Centre for Biomedical Technology (CTB), Universidad Politécnica de Madrid. Campus de

6 Montegancedo, Pozuelo de Alarcón, 28223 Madrid, Spain

$7 \quad *$ E-mail: milagros.ramos@ctb.upm.es

\section{Author Contributions}

9 MRG and AMS conceived the study, participated in its design and coordination and drafted the

10 manuscript. TFC, LC and MD carried out all experimental studies and helped to draft the

11 manuscript.

\section{Funding Sources}

13 This work was supported by Reina Sofia Foundation (to MRG). This study was also funded by

14 the Comunidad de Madrid (Neurotec-S2010/BMD-2460). Work at AMS laboratory was funded

15 by MINECO (SAF2010-17167 and SAF2014-56101-R), Comunidad de Madrid (Neurostem-

16 CM S2010-BMD-2336) and Instituto de Salud Carlos III (RETIC TerCel, RD12/0019/0013).

17 Work at MD laboratory was cofunded by FEDER "Una manera de hacer Europa" and the

18 Comunidad de Madrid (BRADE S2013/ICE-2958).

\section{Conflict of Interest}

20 The authors declare that they have no competing interests.

\section{Acknowledgment}


1 We would like to thank Beatriz Moreno and Soledad Martinez for the excellent technical

2 assistance. We thank Dr. R. Martínez (Cajal Institute, Madrid, Spain) for providing the Iba1

3 antibody.

\section{$4 \quad$ References}

5 (1) (2016) World Alzheimer Report 2016 Improving healthcare for people living with dementia 6 coverage, Quality and costs now and in the future.

7 (2) Apostolova, L. G., Hwang, K. S., Andrawis, J. P., Green, A. E., Babakchanian, S., Morra, J.

8 H., Cummings, J. L., Toga, A. W., Trojanowski, J. Q., Shaw, L. M., Jack, C. R., Petersen, R. C., 9 Aisen, P. S., Jagust, W. J., Koeppe, R. A., Mathis, C. A., Weiner, M. W., and Thompson, P. M. 10 (2010) 3D PIB and CSF biomarker associations with hippocampal atrophy in ADNI subjects.

11 Neurobiol. Aging 31, 1284-1303.

12 (3) Smailagic, N., M, R. F., Ciapponi, A., Giannakou, A., Ol, P., X, B. C., and Cullum, S.

13 (2015) Mini-Mental State Examination ( MMSE ) for the detection of Alzheimer's disease and 14 other dementias in people with mild cognitive impairment ( MCI ) ( Review ). Cochrane 15 Database Syst Rev CD010783.

16 (4) Reiman, E. M., Quiroz, Y. T., Fleisher, A. S., Chen, K., Velez-Pardo, C., Jimenez-Del-Rio, 17 M., Fagan, A. M., Shah, A. R., Alvarez, S., Arbelaez, A., Giraldo, M., Acosta-Baena, N., 18 Sperling, R. A., Dickerson, B., Stern, C. E., Tirado, V., Munoz, C., Reiman, R. A., Huentelman, 19 M. J., Alexander, G. E., Langbaum, J. B. S., Kosik, K. S., Tariot, P. N., and Lopera, F. (2012)

20 Brain imaging and fluid biomarker analysis in young adults at genetic risk for autosomal 21 dominant Alzheimer's disease in the presenilin 1 E280A kindred: A case-control study. Lancet 22 Neurol. 11, 1048-1056.

23 (5) Koffie, R. M., Farrar, C. T., Saidi, L.-J., William, C. M., Hyman, B. T., and Spires-Jones, T.

24 L. (2011) Nanoparticles enhance brain delivery of blood-brain barrier-impermeable probes for 25 in vivo optical and magnetic resonance imaging. Proc. Natl. Acad. Sci. 108, 18837-18842. 
1 (6) Chamberlain, R., Wengenack, T. M., Poduslo, J. F., Garwood, M., and Jack, C. R. (2011)

2 Magnetic resonance imaging of amyloid plaques in transgenic mouse models of Alzheimer's

3 disease. Curr. Med. Imaging Rev. 7, 3-7.

4 (7) Baltes, C., Princz-Kranz, F., Rudin, M., and Mueggler, T. (2011) Detecting amyloid- $\beta$

5 plaques in Alzheimer's disease. Methods Mol. Biol. 711, 511-533.

6 (8) Wisniewski T, B. A. (2010) Vaccination as a therapeutic approach to Alzheimer's disease.

$7 \quad$ Mt Sinai J Med 77, 17-31.

8 (9) Thomas Wisniewskia, A. E. M. S. (2010) Murine models of Alzheimer's disease and their

9 use in developing immunotherapies. Biochim Biophys Acta. 1802, 847-859.

10 (10) Wadghiri, Y. Z., Sigurdsson, E. M., Sadowski, M., Elliott, J. I., Li, Y., Scholtzova, H.,

11 Tang, C. Y., Aguinaldo, G., Pappolla, M., Duff, K., Wisniewski, T., and Turnbull, D. H. (2003)

12 Detection of Alzheimer's amyloid in transgenic mice using magnetic resonance microimaging.

13 Magn. Reson. Med. 50, 293-302.

14 (11) Wadghiri, Y. Z., Li, J., Wang, J., Hoang, D. M., Sun, Y., Xu, H., Tsui, W., Li, Y.,

15 Boutajangout, A., Wang, A., de Leon, M., and Wisniewski, T. (2013) Detection of Amyloid

16 Plaques Targeted by Bifunctional USPIO in Alzheimer's Disease Transgenic Mice Using

17 Magnetic Resonance Microimaging. PLoS One 8, 1-10.

18 (12) Wadghiri YZ, Hoang DM, Wisniewski T, S. E. (2012) In vivo magnetic resonance imaging 19 of amyloid- $\beta$ plaques in mice. Methods Mol Biol 849, 435-451.

20 (13) Benveniste, H., Einstein, G., Kim, K. R., Hulette, C., and Johnson, G. A. (1999) Detection

21 of neuritic plaques in Alzheimer's disease by magnetic resonance microscopy. Proc. Natl. Acad.

22 Sci. 96, 14079-14084.

23 (14) Braakman, N., Matysik, J., Van Duinen, S. G., Verbeek, F., Schliebs, R., de Groot, H. J. 
1 Magn. Reson. Imaging 24, 530-536.

2 (15) Jack, C. R. (2005) In Vivo Magnetic Resonance Microimaging of Individual Amyloid

3 Plaques in Alzheimer's Transgenic Mice. J. Neurosci. 25, 10041-10048.

4 (16) Vanhoutte, G., Dewachter, I., Borghgraef, P., Van Leuven, F., and Van Der Linden, A.

5 (2005) Noninvasive in vivo MRI detection of neuritic plaques associated with iron in

6 APP[V717I] transgenic mice, a model for Alzheimer's disease. Magn. Reson. Med. 53, 607-

7613.

8 (17) Connor, J. R., Menzies, S. L., Martin, S. M. S., and Mufson, E. J. (1992) A Histochemical

9 Study of Iron, Transferrin, and Ferritin in Alzheimer' s Diseased Brains. J. Neurosci. Res. 83, $1075-83$.

11 (18) Meadowcort, M. D., Connor, J. R., Smith, M. B., and Yang, Q. X. (2009) Magnetic

12 Resonance Imaging and Histological Analysis of Beta- Amyloid Plaques in Both Human

13 Alzheimer's Disease and APP/ PS1 Transgenic Mice. J Magn Reson Imaging 29, 997-1007.

14 (19) Yang, C. C., Yang, S. Y., Chieh, J. J., Horng, H. E., Hong, C. Y., Yang, H. C., Chen, K. H., 15 Shih, B. Y., Chen, T. F., and Chiu, M. J. (2011) Biofunctionalized magnetic nanoparticles for 16 specifically detecting biomarkers of Alzheimer's disease in vitro. ACS Chem. Neurosci. 2, 50017505.

18 (20) McLachlan, S. J., Morris, M. R., Lucas, M. A., Fisco, R. A., Eakins, M. N., Fowler, D. R., 19 Scheetz, R. B., and Olukotun, A. Y. (1994) Phase I clinical evaluation of a new iron oxide MR 20 contrast agent. J. Magn. Reson. Imaging 4, 301-307.

21 (21) Wadghiri YZ, Sigurdsson EM, Wisniewski T, T. D. (2005) MR Imaging of amyloid 22 plaques in transgenic mice, in Amyloid proteins: Methods and Protocols (EM, S., Ed.), pp 36523 379. Humana Press Inc, Totowa, New Jersey.

24 (22) Sigurdsson, E. M., Wadghiri, Y. Z., Mosconi, L., Blind, J. A., Knudsen, E., Asuni, A., 25 Scholtzova, H., Tsui, W. H., Li, Y., Sadowski, M., Turnbull, D. H., de Leon, M. J., and 
1 Wisniewski, T. (2008) A non-toxic ligand for voxel-based MRI analysis of plaques in AD

2 transgenic mice. Neurobiol. Aging 29, 836-847.

3 (23) Plissonneau, M., Pansieri, J., Heinrich-Balard, L., Morfin, J.-F., Stransky-Heilkron, N.,

4 Rivory, P., Mowat, P., Dumoulin, M., Cohen, R., Allémann, É., Tóth, É., Saraiva, M. J., Louis,

5 C., Tillement, O., Forge, V., Lux, F., and Marquette, C. (2016) Gd-nanoparticles

6 functionalization with specific peptides for ß-amyloid plaques targeting. J. Nanobiotechnology

$7 \quad 14,60$.

8 (24) Ansciaux, E., Burtea, C., Laurent, S., Crombez, D., Nonclercq, D., Vander Elst, L., and

9 Muller, R. N. (2015) In vitro and in vivo characterization of several functionalized ultrasmall

10 particles of iron oxide, vectorized against amyloid plaques and potentially able to cross the

11 blood-brain barrier: Toward earlier diagnosis of Alzheimer's disease by molecular imag.

12 Contrast Media Mol. Imaging 10, 211-224.

13 (25) Poduslo JF, Hultman KL, Curran GL, Preboske GM, Chamberlain R, Marjańska M, et al.

14 (2011) Targeting vascular amyloid in arterioles of Alzheimer disease transgenic mice with amyloid $\beta$ protein antibody-coated nanoparticles. J Neuropathol Exp Neurol 70, 653-661.

16 (26) Jaruszewski, K. M., Curran, G. L., Swaminathan, S. K., Rosenberg, J. T., Grant, S. C.,

17 Ramakrishnan, S., Lowe, V. J., Poduslo, J. F., and Kandimalla, K. K. (2014) Multimodal

18 Nanoprobes to target cerebrovascular amyloid in Alzheimer's disease brain. Biomaterials 35, 19 1967-1976.

(27) Yin, Z., Yu, T., and Xu, Y. (2015) Preparation of Amyloid Immuno-Nanoparticles as

21 Potential MRI Contrast Agents for Alzheimer's Disease Diagnosis. J. Nanosci. Nanotechnol.

$22 \quad 15,6429-6434$.

23 (28) Siegemund, T., Paulke, B. R., Schmiedel, H., Bordag, N., Hoffmann, A., Harkany, T., 24 Tanila, H., Kacza, J., and Härtig, W. (2006) Thioflavins released from nanoparticles target

25 fibrillar amyloid $\beta$ in the hippocampus of APP/PS1 transgenic mice. Int. J. Dev. Neurosci. 24, $26 \quad 195-201$. 
1 (29) Hu, B., Dai, F., Fan, Z., Ma, G., Tang, Q., and Zhang, X. (2015) Nanotheranostics: Congo

2 Red/Rutin-MNPs with Enhanced Magnetic Resonance Imaging and H2 O2 -Responsive

3 Therapy of Alzheimer's Disease in APPswe/PS1dE9 Transgenic Mice. Adv. Mater. 27

4 (37):5499-5505.

5 (30) Zhang, D., Fa, H.-B., Zhou, J.-T., Li, S., Diao, X.-W., and Yin, W. (2015) The detection of $6 \quad \beta$-amyloid plaques in an Alzheimer's disease rat model with DDNP-SPIO. Clin. Radiol. 70, 74780.

8 (31) Cheng, K. K., Chan, P. S., Fan, S., Kwan, S. M., Yeung, K. L., Wang, Y. X. J., Chow, A.

9 H. L., Wu, E. X., and Baum, L. (2015) Curcumin-conjugated magnetic nanoparticles for 10 detecting amyloid plaques in Alzheimer's disease mice using magnetic resonance imaging 11 (MRI). Biomaterials 44, 155-172.

12 (32) Altamura, S., and Muckenthaler, M. U. (2009) Iron toxicity in diseases of aging:

13 Alzheimer's disease, Parkinson's disease and atherosclerosis. J. Alzheimer's Dis. 16, 879-895.

14 (33) Bartzokis G, T. T. (2000) MRI evaluation of basal ganglia ferritin iron and neurotoxicity in 15 Alzheimer's and Huntingon's disease. Cell Mol Biol 46, 821-833.

16 (34) Sultana, R., Boyd-Kimball, D., Cai, J., Pierce, W. M., Klein, J. B., Merchant, M., and

17 Butterfield, D. A. (2007) Proteomics analysis of the Alzheimer's disease hippocampal

18 proteome. J. Alzheimers. Dis. 11, 153-164.

19 (35) Rogers JT, Bush AI, Cho HH, Smith DH, Thomson AM, Friedlich AL, Lahiri DK, 20 Leedman PJ, Huang X, C. C. (2008) Iron and the translation of the amyloid precursor protein 21 (APP) and ferritin mRNAs: riboregulation against neural oxidative damage in Alzheimer's 22 disease. Biochem Soc Trans 36, 1282-1287.

23 (36) Grundke-Iqbal, I., Fleming, J., Tung, Y. C., Lassmann, H., Iqbal, K., and Joshi, J. G. 24 (1990) Ferritin is a component of the neuritic (senile) plaque in Alzheimer dementia. Acta 25 Neuropathol. 81, 105-110. 
1 (37) Oakley, H., Cole, S. L., Logan, S., Maus, E., Shao, P., Craft, J., Guillozet-Bongaarts, A.,

2 Ohno, M., Disterhoft, J., Van Eldik, L., Berry, R., and Vassar, R. (2006) Intraneuronal $\beta$ -

3 Amyloid Aggregates, Neurodegeneration, and Neuron Loss in Transgenic Mice with Five

4 Familial Alzheimer's Disease Mutations: Potential Factors in Amyloid Plaque Formation. $J$.

5 Neurosci. 26, 10129-10140.

6 (38) Smith, M. A., Harris, P. L., Sayre, L. M., and Perry, G. (1997) Iron accumulation in

7 Alzheimer disease is a source of redox-generated free radicals. Proc. Natl. Acad. Sci. U. S. A.

$8 \quad 94,9866-9868$.

9 (39) Abo-Krysha, N., and Rashed, L. (2008) The role of iron dysregulation in the pathogenesis

10 of multiple sclerosis: an Egyptian study. Mult. Scler. 14, 602-608.

11 (40) Raven, E. P., Lu, P. H., Tishler, T. A., Heydari, P., and Bartzokis, G. (2013) Increased iron

12 levels and decreased tissue integrity in hippocampus of Alzheimer's disease detected in vivo with magnetic resonance imaging. J. Alzheimer's Dis. 37, 127-136.

14 (41) Chen, J., Marks, E., Lai, B., Zhang, Z., Duce, J. A., Lam, L. Q., Volitakis, I., Bush, A. I.,

15 Hersch, S., and Fox, J. H. (2013) Iron Accumulates in Huntington's Disease Neurons:

16 Protection by Deferoxamine. PLoS One 8, 1-12.

17 (42) Mochizuki, H., and Yasuda, T. (2012) Iron accumulation in Parkinson's disease. J. Neural Transm. 119, 1511-1514.

(43) Hametner, S., Wimmer, I., Haider, L., Pfeifenbring, S., Brück, W., and Lassmann, H. (2013) Iron and neurodegeneration in the multiple sclerosis brain. Ann. Neurol. 74, 848-861.

(44) Meadowcroft, M. D., Connor, J. R., and Yang, Q. X. (2015) Cortical iron regulation and inflammatory response in Alzheimer's disease and APP SWE/PS1 $\Delta \mathrm{E} 9$ mice: A histological 23 perspective. Front. Neurosci. 9, 1-16. 
1 (46) Mrak, R.E. (2012) Microglia in Alzheimer brain: a neuropathological perspective. Int J

2 Alzheimers Dis 2012, 165021.

3 (47) Lipman, N. S., Jackson, L. R., Weis-Garcia, F., and Trudel, L. J. (2005) Monoclonal versus

4 polyclonal antibodies: distinguishing characteristics, applications, and information resources.

5 ILAR J. 46, 258-268.

6 (48) Monagle, J. J. (1962) Carbodiimides. III. Conversion of isocyanates to carbodiimides-

7 catalyst studies. J. Org. Chem. 27, 3851-3855.

8 (49) Schmidt, M. L., Robinson, K. A., Lee, V. M., and Trojanowski, J. Q. (1995) Chemical and

9 immunological heterogeneity of fibrillar amyloid in plaques of Alzheimer's disease and Down's

10 syndrome brains revealed by confocal microscopy. Am. J. Pathol. 147, 503-515.

11 (50) Mu, K., Zhang, S., Ai, T., Jiang, J., Yao, Y., Jiang, L., Zhou, Q., Xiang, H., Zhu, Y., Yang,

12 X., and Zhu, W. (2015) Monoclonal antibody-conjugated superparamagnetic iron oxide

13 nanoparticles for imaging of epidermal growth factor receptor-targeted cells and gliomas. Mol.

14 Imaging 14.

15 (51) Novotna, B., Jendelova, P., Kapcalova, M., Rossner, P., Turnovcova, K., Bagryantseva, Y.,

16 Babic, M., Horak, D., and Sykova, E. (2012) Oxidative damage to biological macromolecules in

17 human bone marrow mesenchymal stromal cells labeled with various types of iron oxide

18 nanoparticles. Toxicol. Lett. 210, 53-63.

19 (52) Mahmoudi, M., Monopoli, M. P., Rezaei, M., Lynch, I., Bertoli, F., Mcmanus, J. J., and

20 Dawson, K. A. (2013) The Protein Corona Mediates the Impact of Nanomaterials and Slows

21 Amyloid Beta Fibrillation. ChemBioChem 14, 568-572.

22 (53) Li, L., Fang, C. J., Ryan, J. C., Niemi, E. C., Lebrón, J. a, Björkman, P. J., Arase, H., Torti,

23 F. M., Torti, S. V, Nakamura, M. C., and Seaman, W. E. (2010) Binding and uptake of H-

24 ferritin are mediated by human transferrin receptor-1. Proc. Natl. Acad. Sci. U. S. A. 107, 3505-

253510. 
1 (54) Wallace, D. F., McDonald, C., and Subramaniam, V. N. (2010) Transferrin receptor 1: A

2 ferritin receptor as well? Gastroenterology 139, 1052-1053.

3 (55) Brown, R. C., Egleton, R. D., and Davis, T. P. (2004) Mannitol opening of the blood-brain

4 barrier: Regional variation in the permeability of sucrose, but not $86 \mathrm{Rb}+$ or albumin. Brain Res.

$5 \quad 1014,221-227$.

6 (56) Jing Yang, Youssef Zaim Wadghiri, Dung Minh Hoang, Wai Tsui, Yanjie Sun, E., and

7 Chung, Yongsheng Li, Andrew Wang, M. de L. and T. W. (2011) Detection of Amyloid

8 Plaques Targeted by USPIO-A $\beta 1-42$ in Alzheimer's Disease Transgenic Mice using Magnetic

9 Resonance Microimaging. Neuroimage 55, 1600-1609.

10 (57) Bush, A. I., and Tanzi, R. E. (2008) Therapeutics for Alzheimer's disease based on the 11 metal hypothesis. Neurotherapeutics 5, 421-432.

12 (58) Hall, a P., Davies, W., Stamp, K., Clamp, I., and Bigley, A. (2013) Comparison of

13 Computerized Image Analysis with Traditional Semiquantitative Scoring of Perls' Prussian Blue Stained Hepatic Iron Deposition. Toxicol. Pathol. 992-1000.

(59) Bussière, T., Bard, F., Barbour, R., Grajeda, H., Guido, T., Khan, K., Schenk, D., Games, D., Seubert, P., and Buttini, M. (2004) Morphological characterization of Thioflavin-S-positive 17 amyloid plaques in transgenic Alzheimer mice and effect of passive Abeta immunotherapy on their clearance. Am. J. Pathol. 165, 987-995. Receptor-Conjugated Gold Nanorods to Induce Cell Death in Glioblastoma Cell Lines. $J$.

23 Nanosci. Nanotechnol. 16, 7689-7695. and Díaz-Nido, J. (1999) Lithium protects cultured neurons against beta-amyloid-induced 
1 neurodegeneration. FEBS Lett. 453, 260-264.

2 (63) Berridge, M. V., Herst, P. M., and Tan, A. S. (2005) Tetrazolium dyes as tools in cell

3 biology: New insights into their cellular reduction. Biotechnol. Annu. Rev. 11, 127-152.

4 (64) Yardeni, T., Eckhaus, M., Morris, H. D., Huizing, M., and Hoogstraten-Miller, S. (2011)

5 Retro-orbital injections in mice. Lab Anim. (NY). 40, 155-160.

\section{$6 \quad$ Figure captions}

7 Figure 1: Iron, amyloid, and ferritin accumulation in 5XFAD mice. Coronal brain sections 8 of nontransgenic (A, $\mathbf{C}$, and $\mathbf{E})$ and $5 \mathrm{XFAD}$ transgenic $(\mathbf{B}, \mathbf{D}$, and $\mathbf{F})$ mice stained with: $\mathbf{A}$ and

9 B) Prussian blue to detect iron accumulation; $\mathbf{C}$ and $\mathbf{D})$ Thioflavin $\mathrm{S}$ to label amyloid plaques; 10 and $\mathbf{E}$ and $\mathbf{F}$ ) an anti-ferritin antibody to detect the protein ferritin. No obvious label of any 11 markers can be detected in nontransgenic mice, while the subiculum in 5XFAD mice showed a 12 strong labeling for iron (arrow in $\mathbf{B}$ ), amyloid plaques (arrow in $\mathbf{D}$ ), and ferritin (arrow in $\mathbf{F}$ ).

13 Scale bars in A and B: $200 \mu \mathrm{m}$ and in C-F: $500 \mu \mathrm{m}$.

14 Figure 2: Spatial relationship between ferritin and amyloid plaques in 5XFAD mice. Serial 15 confocal microscopy images obtained every $5 \mu \mathrm{m}$ from the top of the section to the bottom (A through $\mathrm{D}$ ) in the $\mathrm{Z}$ axis from the subiculum of a $5 \mathrm{XFAD}$ mouse. Coronal brain sections were labeled with an antibody anti-ferritin (red) and Thioflavin S (green) to detect the presence of 18 ferritin and amyloid plaques, respectively. Scale bar: $25 \mu \mathrm{m}$.

Figure 3: Cell types that accumulate ferritin in 5XFAD mice. A) Coronal brain section of a 5XFAD mouse stained with an anti-ferritin antibody showing the accumulation of ferritin in the subiculum area (arrow). B) Higher magnification of the same anatomical region showing a high regional colocalization of amyloid plaques stained with Thioflavin $\mathrm{S}$ (green) and the anti-ferritin antibody (red). C) Sections stained with the astrocytic marker GFAP (green) showed a high number of GFAP-positive cells throughout the subiculum area with no colocalization with the ferritin-positive cells (red). D) Microglial cells in the subiculum area labeled with tomato lectin 
1 (green) showing a high degree of colocalization (yellow) with the ferritin stain (anti-ferritin

2 antibody in red). Scale bars in A: $500 \mu \mathrm{m}$; in B-D: $100 \mu \mathrm{m}$.

3 Figure 4: Dot-blot assay to determine the effectiveness of the anti-ferritin antibody

4 coupling to MNPs. One $\mu$ l of A) anti-ferritin antibody used for the coupling reaction, B) MNPs

5 functionalized with the anti-ferritin antibody, C) supernatant after the coupling reaction (anti-

6 ferritin antibody not bound to MNPs), and D) MNPs used as a negative control. Note that a very

7 high fraction of the initial antibody present in the coupling reaction did bind to the MNPs.

8 Figure 5: Cell viability after incubation with magnetic nanoparticles. Analysis of the

9 viability of human neuroblastoma SH-SY5Y cells (A) and neuronal-glia mixed primary cell

10 cultures obtained from mouse brains (B) exposed to increasing concentrations of MNPs and

11 MNP-anti-ferritin for 72 hours, assessed by the LDH and XTT assays, respectively. No

12 remarkable changes in cell viability were observed when cells were exposed to increasing

13 concentrations of both types of MNPs for 72 hours. Cell viability in LDH and XTT assays was considered maximum (100\%) when cells were incubated without MNPs. The number of neurons, astrocytes and microglial cells did not show any changes when primary cell cultures obtained from mouse brains were incubated with either MNPs or MNPs-anti-ferritin (C).

17 Microfluorescence images of red fluorescent MNPs-treated cell cultures stained with anti- $\beta$-III-

18 tubulin (neurons), anti-GFAP (astrocytes) and anti-Ibal (microglia) in green show that the

19 nanoparticles are uptaken preferentially by microglial cells (D). Inserts in D show single

20 staining for fluorescent MNPs (red) and microglial cells stained with anti-Iba-1 (green). Nuclei

21 were counterstained with Hoechst (blue). Each value in the graph bars represents the mean \pm

22 SEM of $\mathrm{n}=3$ independent experiments. ANOVA followed by the post-hoc Tukey's test

23 revealed the absence of significant differences $(\mathrm{p}>0.05)$ for each group compared to untreated

24 cells with MNPs. Scale bar in D: $50 \mu \mathrm{m}$.

25 Figure 6: In vitro specificity of the MNP-anti-ferritin conjugate. Coronal brain sections of 
1 the accumulation of this protein in the subiculum region (boxes in $\mathbf{A}$ and $\mathbf{E}$ ). Note the high

2 accumulation of ferritin in 5XFAD brain compared to nontransgenic mice. Coronal brain

3 sections of 5XFAD (B-D) and nontransgenic (F-H) mice, adjacent to those shown in $\mathbf{A}$ and $\mathbf{E}$

4 respectively, were incubated first with the nanoconjugate MNP-anti-ferritin and then with a

Scale bars: A and E: $500 \mu \mathrm{m}$; B-D and F-H: $50 \mu \mathrm{m}$.

Figure 7: In vivo specificity of the MNP-anti-ferritin conjugate in 5XFAD mice. Coronal brain section of a 5XFAD mouse showing $\mathbf{A}$ ) the accumulation of ferritin (red) and amyloid plaques stained with Thioflavin S (green);

B) the subiculum region of a 5XFAD mouse previously injected intravenously with the MNP-anti-ferritin conjugate, showing the presence of used (F-H). Scale bars: A and B: $100 \mu \mathrm{m} ; \mathbf{C}-\mathbf{H}: 50 \mu \mathrm{m}$.

Figure 8: Ex vivo MRI in 5XFAD mice. Ex vivo MR images used to determine absolute T2* values (msec) in regions of interest (ROIs), which were the left and right hippocampus of 
1

2

3

4

5

6

7

8

10

11

12

13

14

15

16

17

18

19

20

21

22

23

24

25

26

27

28

29

30

31

32

33

34

35

36

37

38

39

40

41

42

43

44

45

46

47

48

49

50

51

52

53

54

55

56

57

58

59

60
1 corresponding to the T2* value obtained in the analyzed ROIs of the left and right hippocampus

2 in 5XFAD mice injected with MNPs versus MNP-anti-ferritin $(* \mathrm{p}<0.05$; ANOVA followed by

3 the post-hoc Tukey's test).

4

5

6

7

8

9

10 
Potential use of the MNP-anti-ferritin nanoconjugate as an effective MRI contrast agent for the diagnosis of Alzheimer's disease
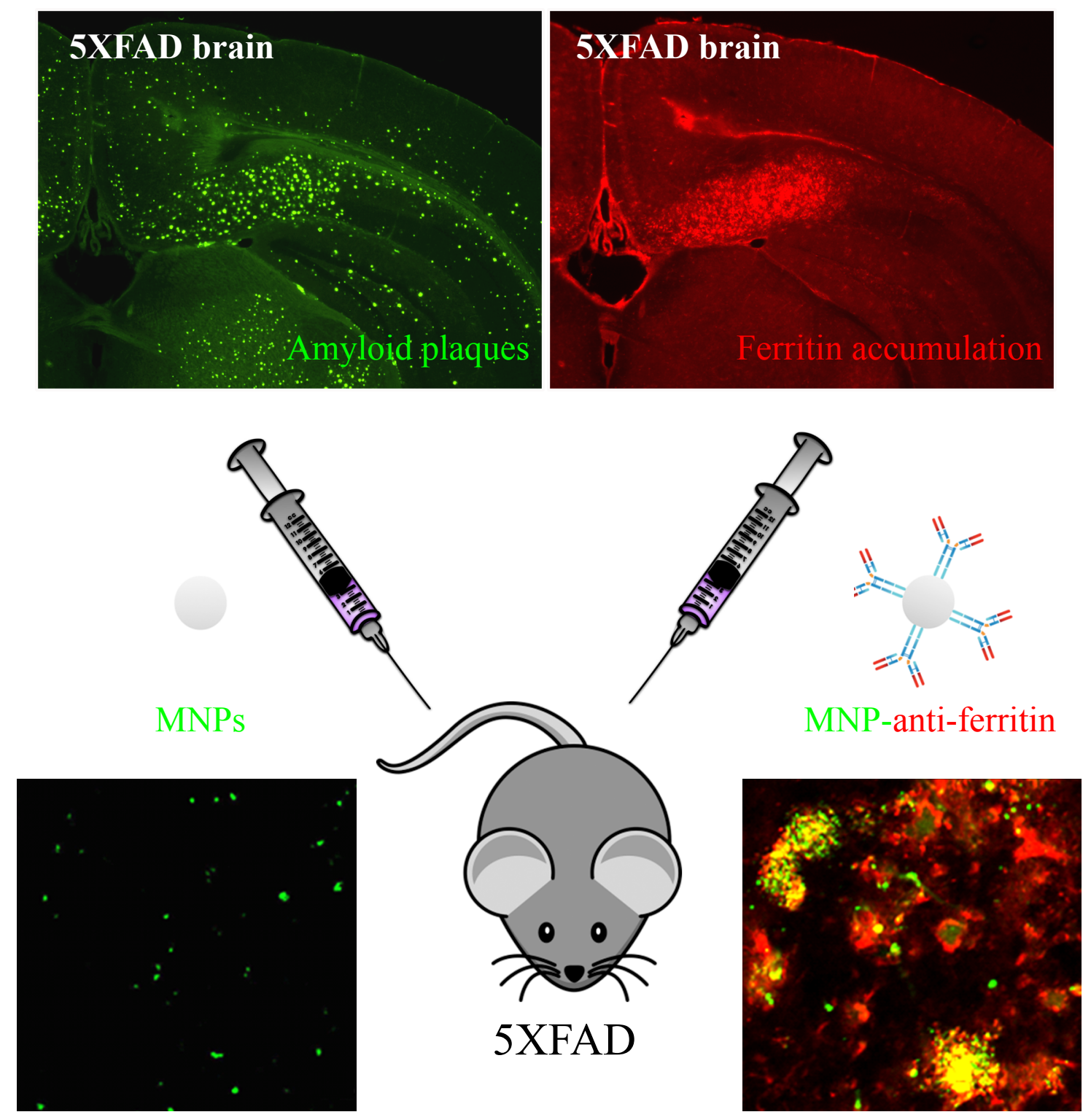

Non-functionalized MNPs

MNP-anti-ferritin conjugates do not bind to 5XFAD brainscs Paragon Plus Environmespecifically bind to 5XFAD brains 

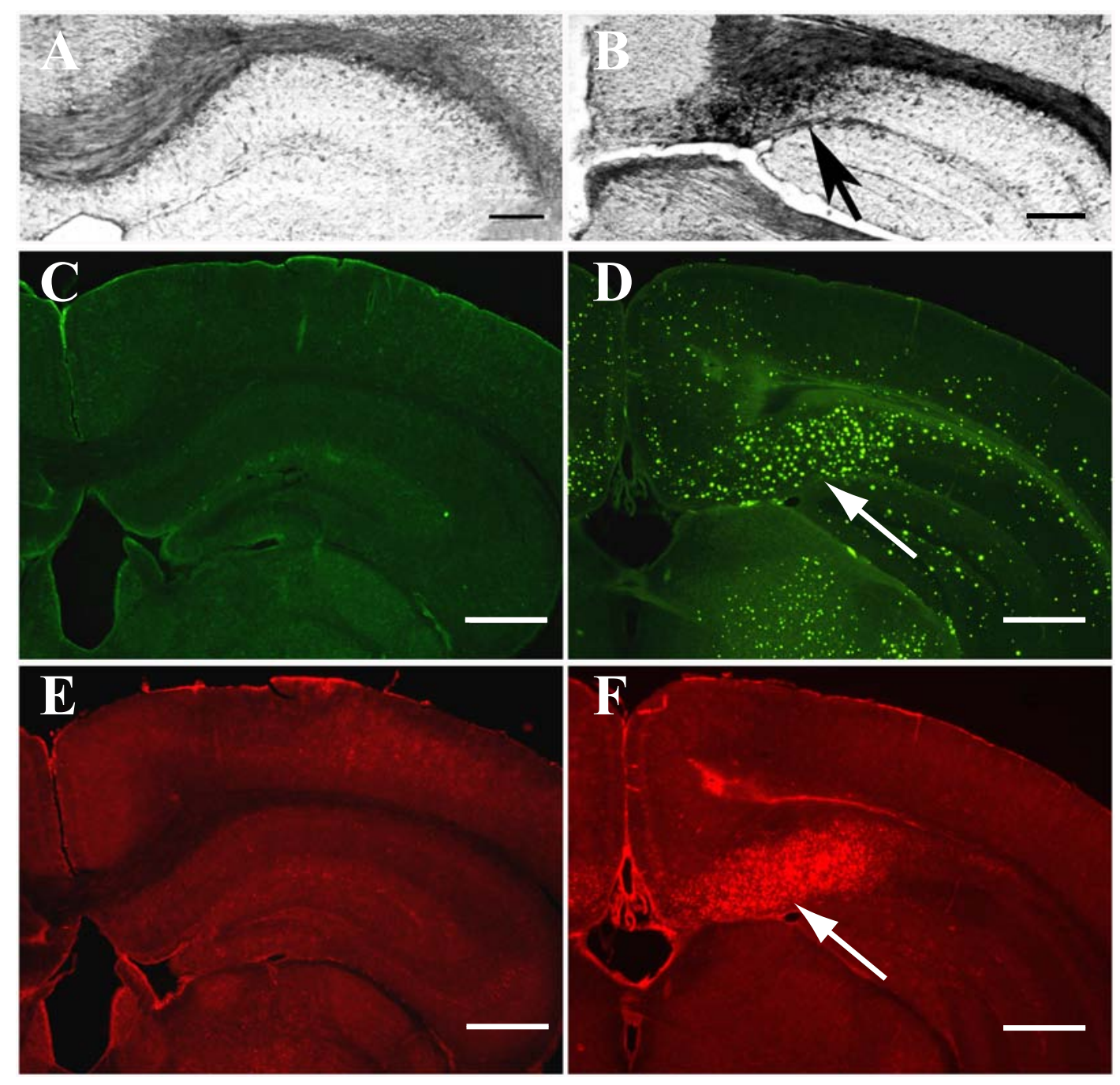

\section{Figure 1}




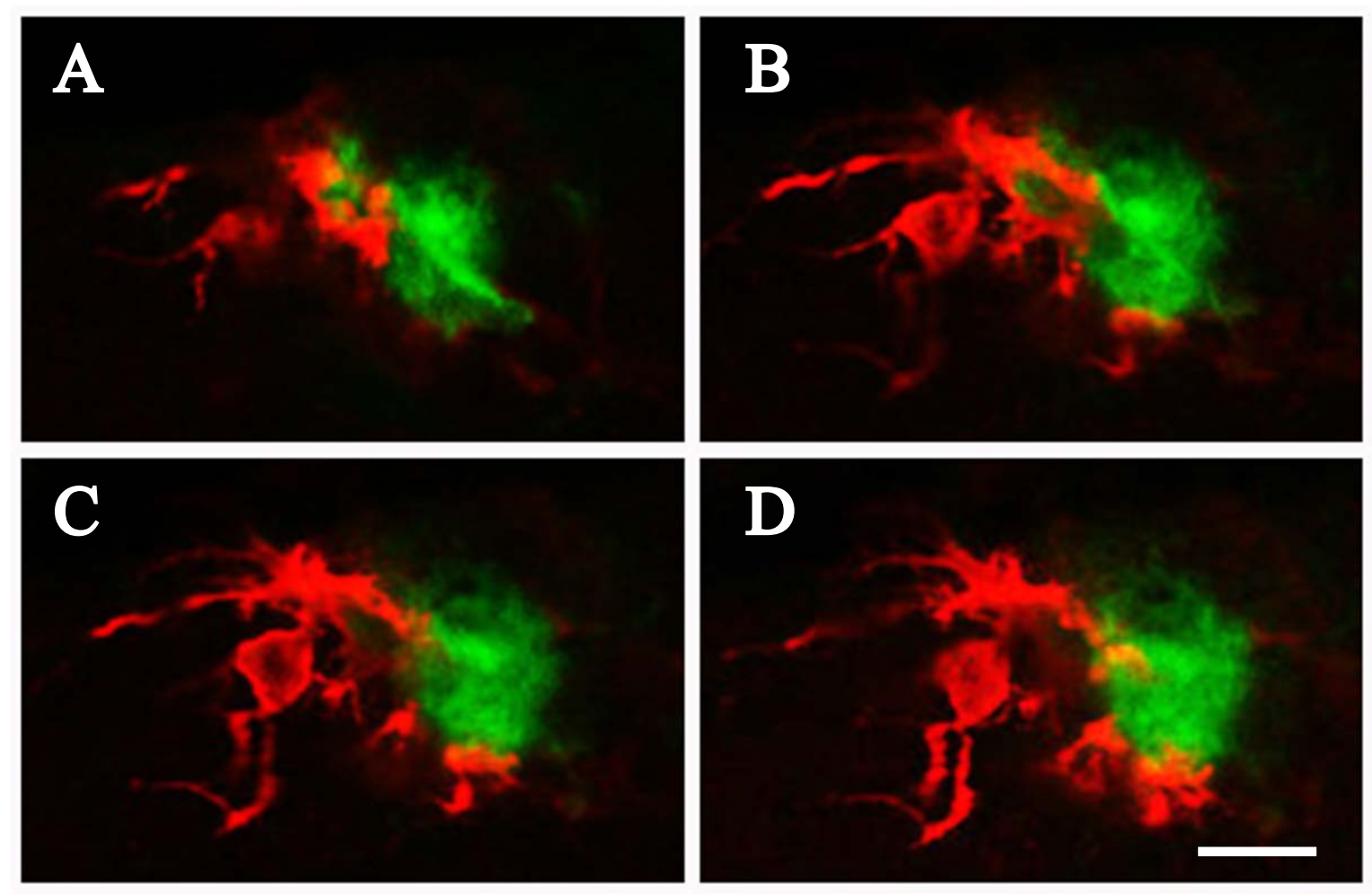

Figure 2 


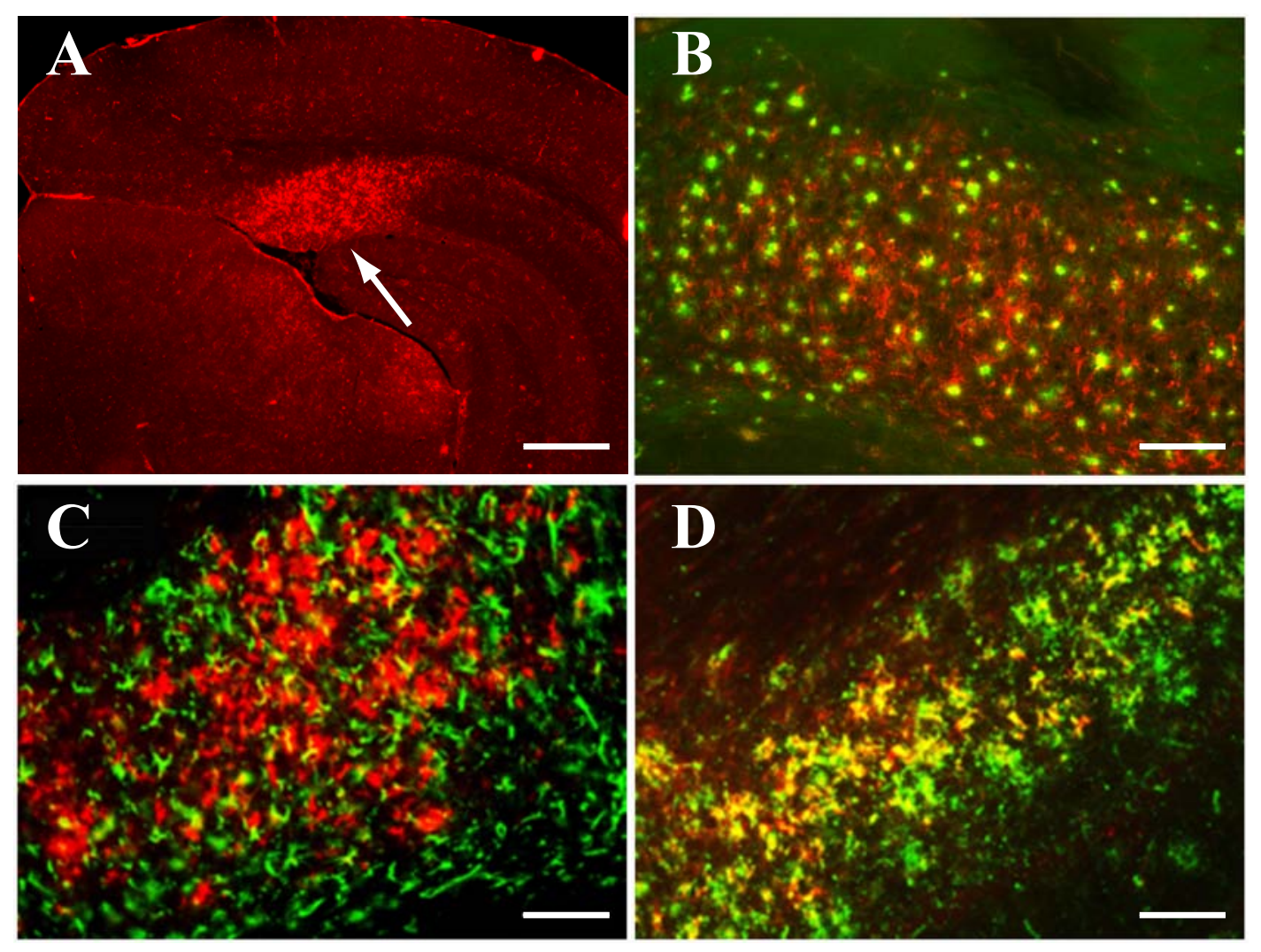

Figure 3 


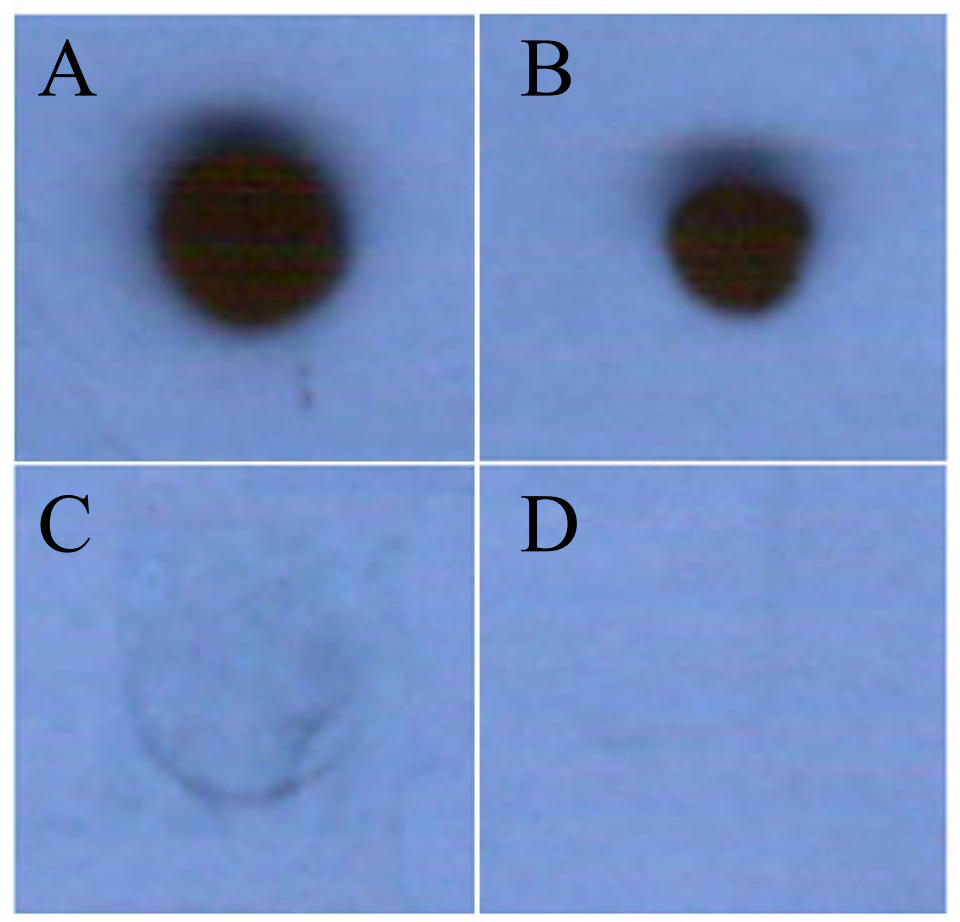

Figure 4 


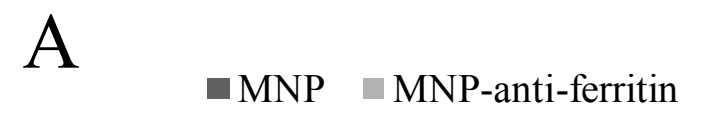

这

Control MNPs $\square$ MNPs-anti-ferritin

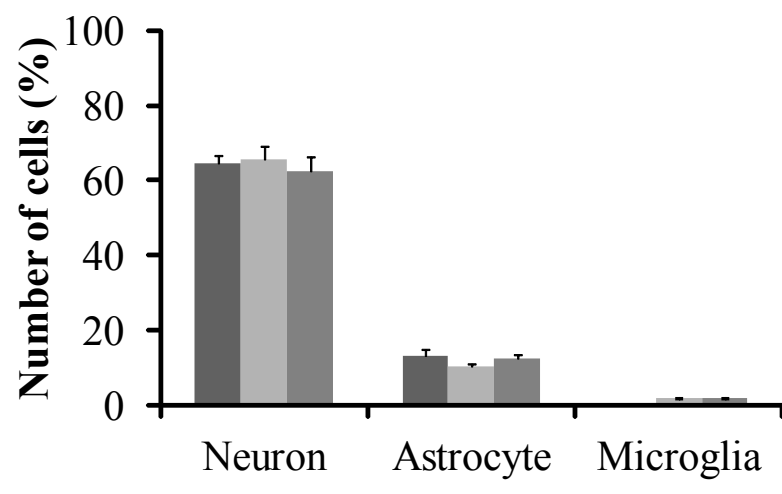

B

$\square$ MNPs $\square$ MNPs-anti-ferritin

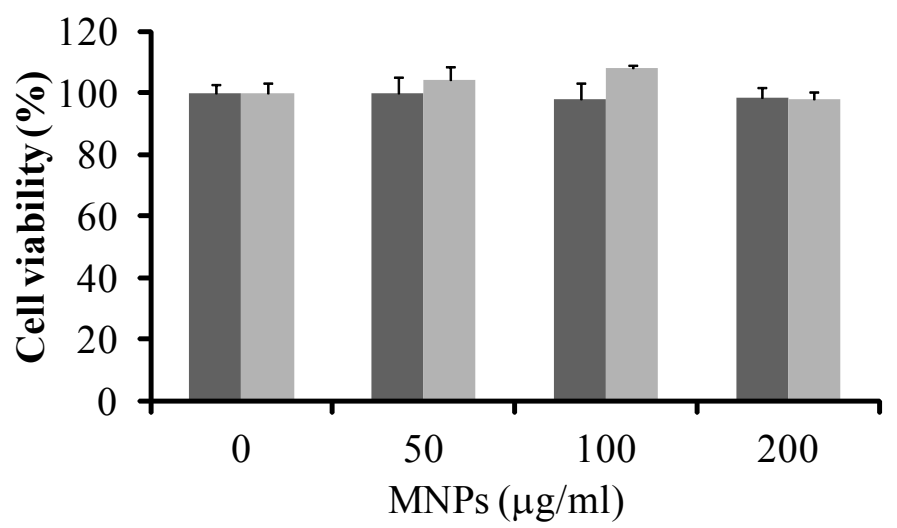

D

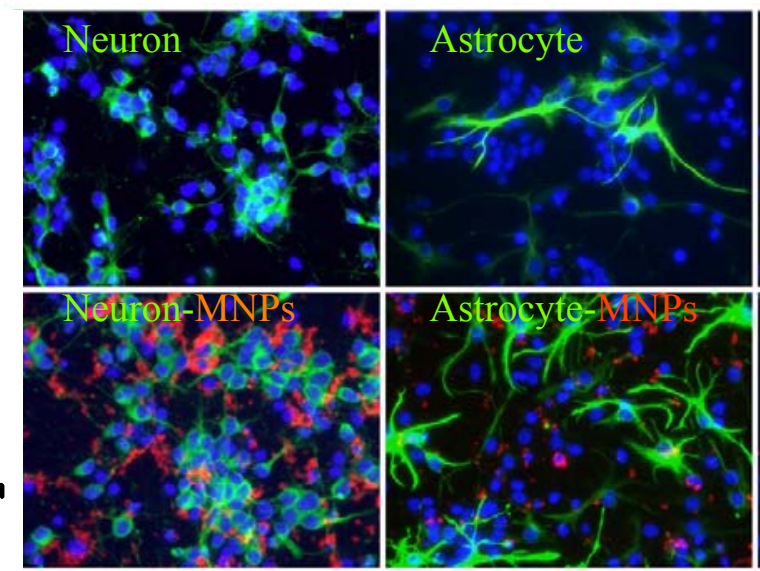

Microglia
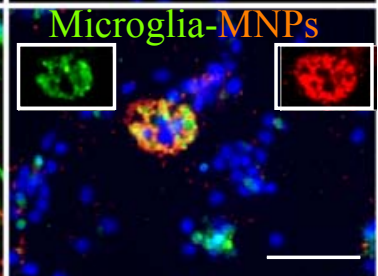

\section{Figure 5}



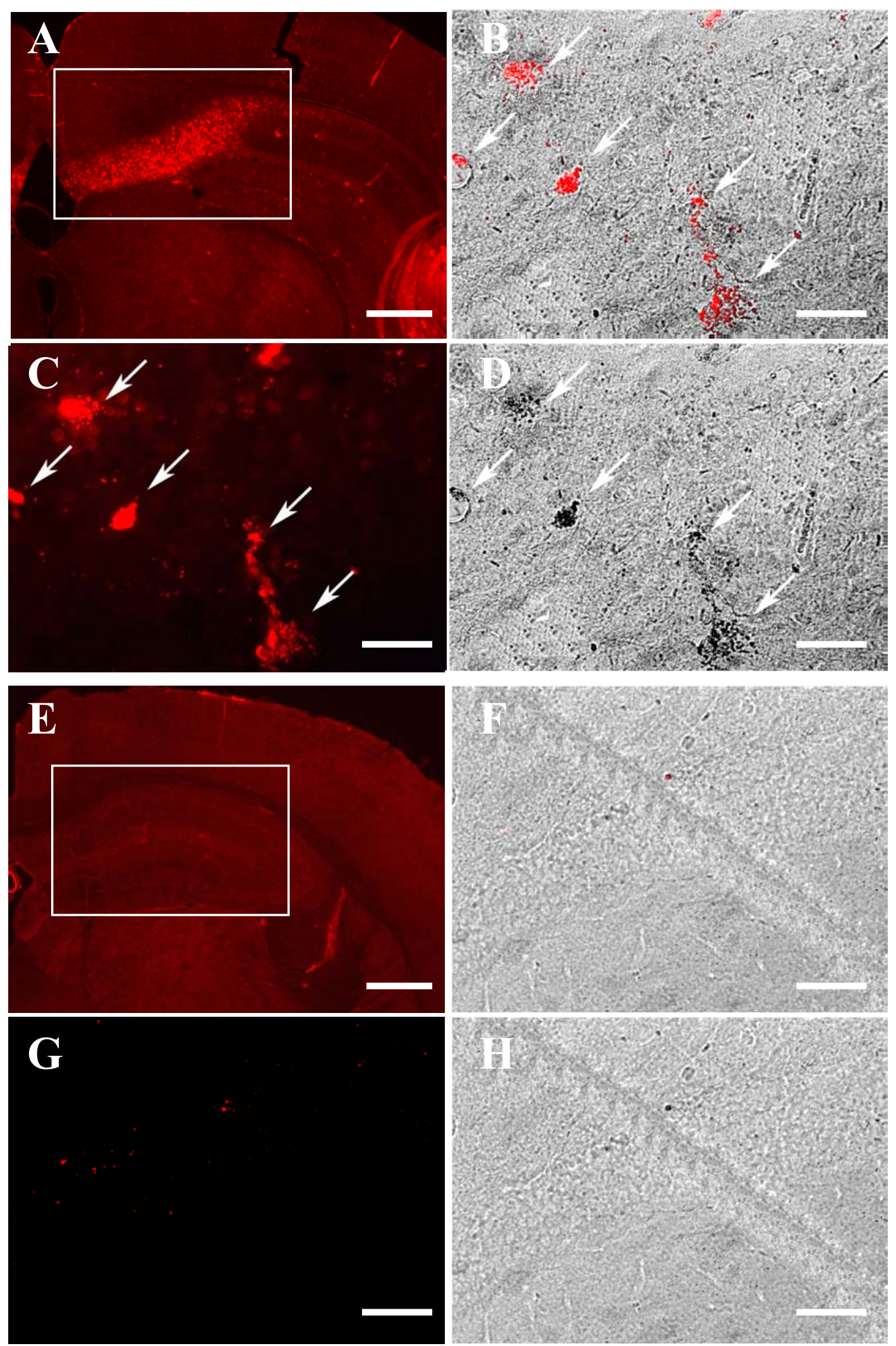

Figure 6 

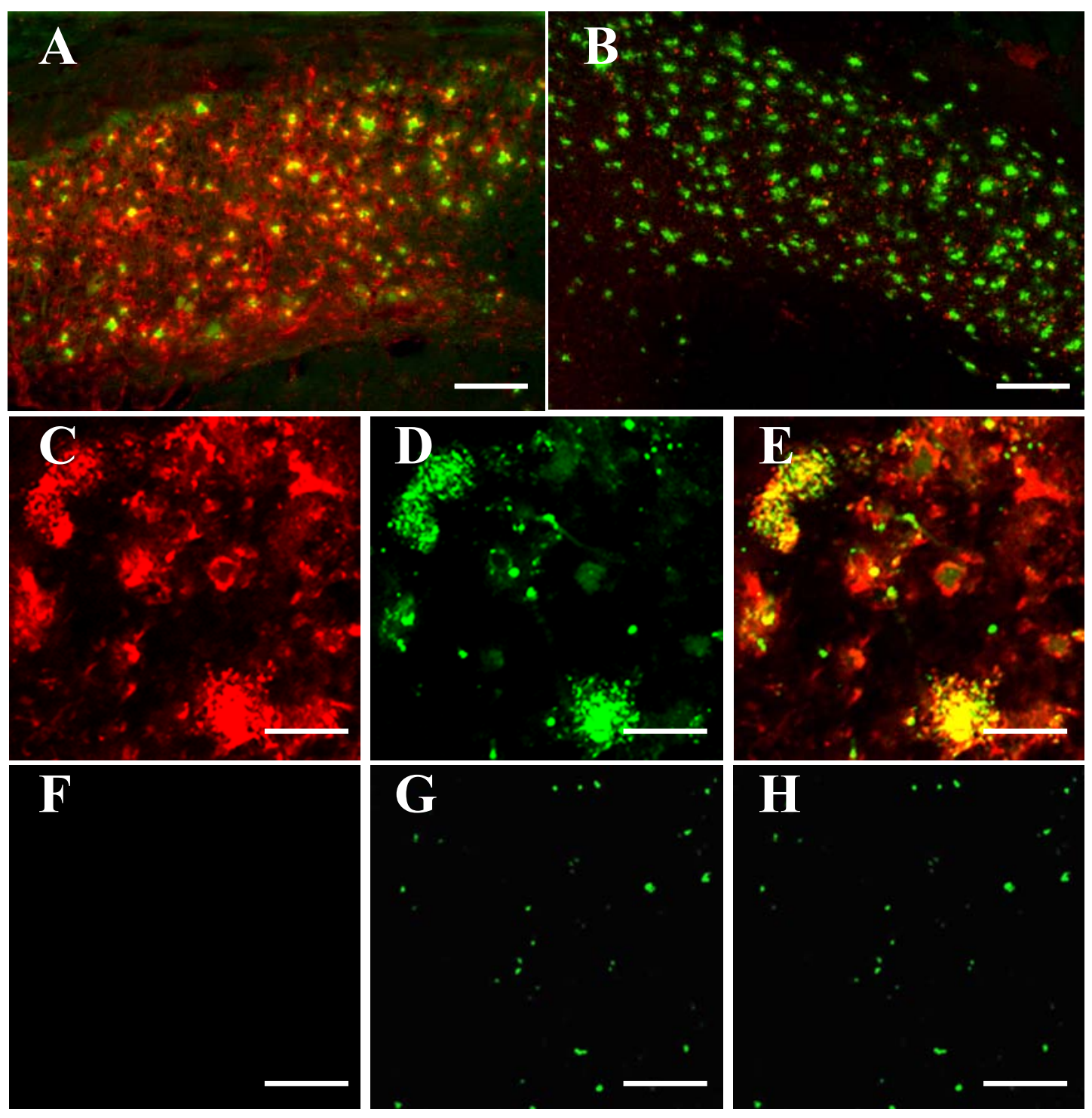

Figure 7 

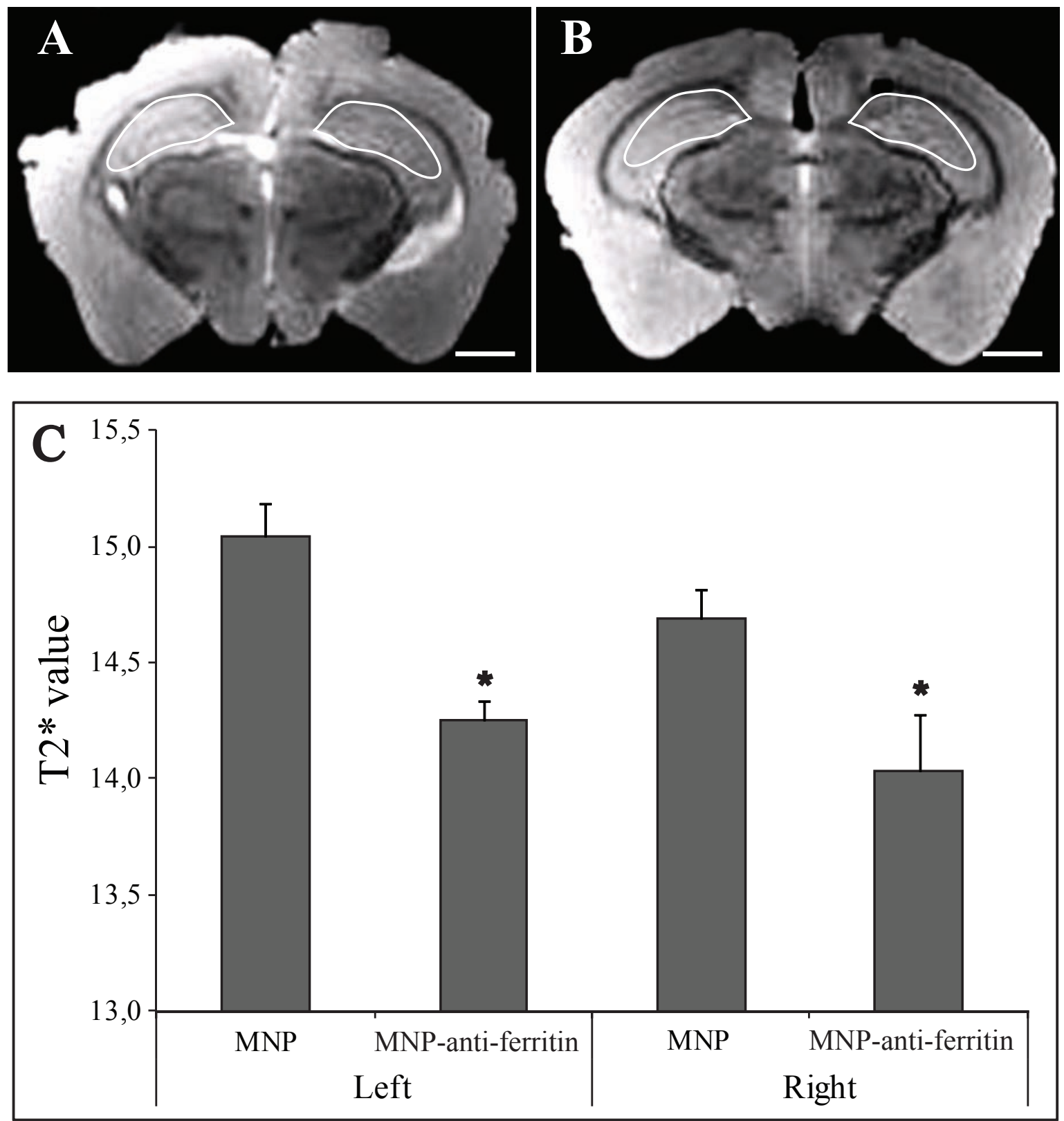

Figure 8 